\title{
Tropospheric aerosol size distributions simulated by three online global aerosol models using the M7 microphysics module
}

\author{
K. Zhang ${ }^{1,2}$, H. Wan ${ }^{2}$, B. Wang ${ }^{1}$, M. Zhang ${ }^{3}$, J. Feichter ${ }^{2}$, and X. Liu ${ }^{4}$ \\ ${ }^{1}$ LASG, Institute of Atmospheric Physics, Chinese Academy of Sciences, Beijing, China \\ ${ }^{2}$ Max Planck Institute for Meteorology, Hamburg, Germany \\ ${ }^{3}$ LAPC, Institute of Atmospheric Physics, Chinese Academy of Sciences, Beijing, China \\ ${ }^{4}$ Pacific Northwest National Laboratory, Richland, WA, USA
}

Received: 21 January 2010 - Published in Atmos. Chem. Phys. Discuss.: 1 March 2010

Revised: 15 June 2010 - Accepted: 6 July 2010 - Published: 14 July 2010

\begin{abstract}
Tropospheric aerosol size distributions are simulated by three online global models which employ exactly the same aerosol microphysics module, but differ in many aspects such as model meteorology, natural aerosol emission, sulfur chemistry, and deposition processes. The main purpose of this study is to identify the influence of these differences on the aerosol simulation. Number concentrations of different aerosol size ranges are compared among the three models and against observations. Overall all three models are able to capture the basic features of the observed spatial distribution. The magnitude of number concentration is consistent among the three models in all size ranges, although quantitative differences are also clearly detectable. For the soluble and insoluble coarse and accumulation modes, intermodel discrepancies result primarily from the different parameterization schemes for sea salt and dust emission, and are also linked to the different strengths of the convective transport in the meteorological models. As for the nucleation mode and the soluble Aitken mode, the spread of model results appear largest in the tropics and in the middle and upper troposphere. Diagnostics and sensitivity experiments suggest that this large spread is directly related to the sulfur cycle in the models, which is strongly affected by the choice of sulfur chemistry scheme, its coupling with the convective transport and wet deposition calculation, and the related meteorological fields such as cloud cover, cloud water content, and precipitation. Aerosol size distributions simulated by the three
\end{abstract}

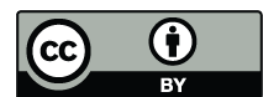

Correspondence to: K. Zhang (kai.zhang@zmaw.de) models are compared against observations in the boundary layer. The characteristic shape and magnitude of the distribution functions are reasonably reproduced in typical conditions of clean, polluted and transition areas.

\section{Introduction}

Although research has been going on for several decades, the effect of aerosols on the Earth's climate system, particularly through its impact on clouds, remains controversial (Stevens and Feingold, 2009). Possible mechanisms have been proposed and simulated using numerical models (Schulz et al., 2006; Lohmann et al., 2007), but large uncertainties remain (IPCC, 2007). The pathway and efficiency of the climate impact of aerosols are not only determined by their chemical composition and the associated physical and chemical properties, but also strongly related to the size distribution of the aerosol population. The diameter of aerosol particles covers a wide range from $10^{-3} \mu \mathrm{m}$ to $10^{1} \mu \mathrm{m}$; the size distribution of the aerosol population varies strongly in space and time. Inaccurate representation of these variations is a significant source of uncertainties in the assessment of the climate impact of aerosols. What further complicates the situation is that the representation of size distribution in numerical models interacts with other aerosol-related processes, including the microphysical and chemical processes, deposition, and other removal mechanisms.

Based on harmonized diagnostics, the Aerosol Model Intercomparison Initiative AeroCom (http://nansen.ipsl. jussieu.fr/AEROCOM/) has carried out analysis of aerosol

Published by Copernicus Publications on behalf of the European Geosciences Union. 
simulations from various complex global models (Textor et al., 2006, 2007). It is found that even in terms of global and annual average, the aerosol life cycles and particle sizes simulated by different models spread over large ranges. The models involved in the studies of Textor et al. $(2006,2007)$ feature a high diversity in the configuration, including technical aspects like spatial resolution and source of meteorological fields, conceptual aspects like the mathematical representation of aerosol size distribution, and the parameterization schemes of various aerosol-related physical and chemical processes. Probably all these highly interrelated aspects have contributed to the detected discrepancies among the models. As mentioned in Textor et al. (2006), in order to explain the differences between the simulations, to identify the weak components and find ways to improve the models, it is necessary to examine the aforementioned contributors in an isolated manner. Theoretically, one should carry out sensitivity experiments by changing one parameter of a single contributor at a time. For example, in the work of Liu et al. (2007) a bulk aerosol model was used to analyze differences in aerosol mass distribution and anthropogenic aerosol direct forcing caused solely by changes in meteorological fields. In terms of aerosol physics and chemistry, however, given the vastly different schemes and configurations employed in existing models, we will have to perform a prohibitively large number of simulations in order to cover all possible combinations. Sensitivity experiments thus need to be carried out in a more efficient way.

In this study we use three aerosol-climate model systems to investigate the discrepancies among model results under the condition that the same mathematical method is used to represent the size distribution of the atmospheric aerosols and the same schemes are used for aerosol microphysics. All three model systems are global atmospheric general circulation models (AGCMs) coupled with online aerosol modules. The two aerosol modules involved are the Hamburg Aerosol Module (HAM) of Stier et al. (2005) and the Lasg/IAP Aerosol Module (LIAM) of Zhang (2008). Both modules simulate five aerosol types: sulfate (SU), black carbon (BC), particulate organic matter (POM), sea salt (SS) and dust (DU); the same aerosol microphysics scheme M7 (Vignati et al., 2004) is employed, which uses the modal method for describing aerosol size distribution. Other aerosol processes in HAM and LIAM, including the emissions of SS and DU, sulfur chemistry and deposition, differ to different extents. A detailed comparison of the two aerosol modules is presented in Sects. 2.3 to 2.6.

The three AGCMs used in this study include the ECHAM5 model (Roeckner et al., 2003, 2006) of the Max Planck Institute for Meteorology, the CAM3 model (Collins et al., 2004) of the National Center for Atmospheric Research, and the GAMIL model (Wang et al., 2004; Wan et al., 2006; Zhang et al., 2008) developed at the Institute of Atmospheric Physics in Beijing, China. All three models have been evaluated against the observed climate, used in various applica- tions, and involved in the IPCC AR4 simulations. The similarities and differences among the three GCMs are summarized in Sect. 2.1.

In the literature and in the modeling practice, various mathematical approaches have been used to represent aerosol size distribution, including the bulk method (Feichter et al., 1996; Liousse et al., 1996), the bin method (also called sectional or spectral method, Weisenstein et al., 1997; Jacobson et al., 2001; Spracklen et al., 2005), the modal method (see text below), and the moment method (McGraw, 1997; Bauer et al., 2008). The latter three allow for temporal and spatial-dependent size distributions, among which the sectional and modal methods are widely used in recent years. The modal approach assumes the aerosol population can be described by a number of (typically log-normal) distribution functions, called modes. The aerosol dynamics equations are written in terms of the aerosol number concentration, median diameter (or particle mass), and the variance of the distribution function of each mode (Whitby et al., 1991; Whitby and McMurry, 1997; Wilson et al., 2001). This approach has the advantage of a good balance between the numerical accuracy and the computational cost (Whitby and McMurry, 1997). Since the late 1990's, several aerosol modules aiming at global modeling have been developed based on this approach (Wilson, 1996; Vignati et al., 2004; Easter et al., 2004; Herzog et al., 2004), and implemented in chemical transport models or coupled online with global climate models (Wilson et al., 2001; Ghan et al., 2001; Easter et al., 2004; Liu et al., 2005; Stier et al., 2005). Although all based on the same concept of size distribution representation, these modules differ in many detailed aspects. For example, the total number of modes, the aerosol composition of each mode, and the control parameters of the distribution functions vary considerably from module to module. Since these details are directly linked to aerosol microphysics, the differences can lead to discrepancies in the final simulation results.

The aerosol module HAM has been implemented in the climate model ECHAM5 (Stier et al., 2005), while LIAM in CAM3 and GAMIL (Zhang, 2008). With the three model systems, simulations of the global aerosol concentrations are performed at similar spatial resolutions and under similar emissions. In the present study the mathematical representation of the aerosol size distribution is exactly the same in the three model systems. The comparison of the simulations thus sheds some light on the magnitude of the discrepancies induced exclusively by the meteorological fields, parameterization of aerosol sources and sinks, and their implementation in global models.

The two models GAMIL-LIAM and CAM3-LIAM use the same aerosol module LIAM. The differences in the corresponding simulations thus reflects the impact of model meteorology and the large scale transport; the comparison between the ECHAM5-HAM results with those from the other two models can provide the spread of the simulations caused by differences in the sulfur chemistry, deposition processes 
Table 1. Summary of the main features of the three AGCMs used in this study.

\begin{tabular}{|c|c|c|c|}
\hline & GAMIL & CAM3 & ECHAM5 \\
\hline Dynamical core & $\begin{array}{l}\text { Finite difference } \\
\text { pressure-based sigma coordinate }\end{array}$ & $\begin{array}{l}\text { Spectral transform } \\
\text { hybrid vertical coordinate }\end{array}$ & $\begin{array}{l}\text { Spectral transform } \\
\text { hybrid vertical coordinate }\end{array}$ \\
\hline Resolution & $2.8^{\circ} \times 2.8^{\circ} \mathrm{L} 26$ & $2.8^{\circ} \times 2.8^{\circ}(\mathrm{T} 42) \mathrm{L} 26$ & $2.8^{\circ} \times 2.8^{\circ}(\mathrm{T} 42) \mathrm{L} 19$ \\
\hline Time step for dynamics & $4 \min$ & $20 \mathrm{~min}$ & $30 \mathrm{~min}$ \\
\hline Time step for physics & $20 \min$ & $20 \mathrm{~min}$ & $30 \mathrm{~min}$ \\
\hline Advection & Lin and Rood (1996) (van Leer) & Semi-lagrangian & Lin and Rood (1996) (PPM) \\
\hline Prognostic condensate & $\begin{array}{l}\text { Cloud water concentration is a di- } \\
\text { agnostic variable. Cloud ice is } \\
\text { scaled from cloud water. Neither } \\
\text { is transported. }\end{array}$ & $\begin{array}{l}\text { Cloud water and cloud ice are } \\
\text { treated as tracers. }\end{array}$ & $\begin{array}{l}\text { Cloud water and cloud ice are } \\
\text { treated as tracers. }\end{array}$ \\
\hline Precipitation & Rasch and Kristjansson (1998) & $\begin{array}{l}\text { Rasch and Kristjansson (1998) with } \\
\text { modification by Zhang et al. (2003) }\end{array}$ & Lohmann and Roeckner (1996) \\
\hline Moist convection & \multicolumn{2}{|c|}{$\begin{array}{l}\text { Zhang and McFarlane (1995) for deep convection; Hack } \\
\text { (1994) for shallow/middle tropospheric convection }\end{array}$} & $\begin{array}{l}\text { Tiedtke (1989) with modifications } \\
\text { by Nordeng (1994) }\end{array}$ \\
\hline Vertical diffusion & \multicolumn{2}{|c|}{ Holtslag and Boville (1993) } & Louis (1979) and Brinkop (1995) \\
\hline Radiation & \multicolumn{2}{|c|}{$\begin{array}{l}\text { Briegleb (1992) and Collins et al. (2004) for shortwave; } \\
\text { Mlawer et al. (1997) and Morcrette et al. (1998) for } \\
\text { longwave. }\end{array}$} & Fouquart and Bonnel (1980) \\
\hline
\end{tabular}

and the sequence of calculations in the numerical model (i.e., the operator splitting) in addition to meteorology. Regarding the analysis of the model results, the same modal method in the three models makes it possible to directly compare the simulated aerosol mass and number concentrations of each size range, without having to perform any additional conversion. Simulations from the three models are also evaluated against the observational data in exactly the same manner. To the best of our knowledge, such comparisons have not been seen in the literature ${ }^{1}$.

We are fully aware that the three models discussed here differ from each other in a number of aspects, and so do the simulated results. It is not possible to describe all the discrepancies in a single paper, not to mention the attribution of the discrepancies. As the first step, we focus in this paper on the aerosol size distribution as represented by the number concentrations of the seven modes defined in the M7 microphysics module. Observations of aerosol size in the troposphere over land and ocean are utilized to examine whether the model results are within the reasonable range. Sensitivity experiments are also performed to provide possible explanations for the most evident discrepancies among the three models.

\footnotetext{
${ }^{1}$ Textor et al. (2006) have compared the particle sizes simulated by sixteen different aerosol models. Due to the difficulty in compiling results produced from dramatically different schemes and parameters of the aerosol size distribution, the comparison therein was carried out in a relatively crude way, by splitting the total aerosol mass into only two size ranges and using $d=1 \mu \mathrm{m}$ as the boundary between the "fine" and "coarse" modes.
}

The rest of this paper is organized as follows: a description of the models used in this study as well as their similarities and differences are described in Sect. 2. Section 3 presents the simulated global aerosol mass budgets, which gives an overview of the aerosol life cycles in the three models, and the first picture of the inter-model discrepancies. Global distributions of the aerosol number concentrations are analyzed in Sect. 4. The comparison with observations is presented in Sect. 5 and Sect. 6. Section 7 summarizes the work and draws the conclusions.

\section{Model description}

In this section we describe the three AGCMs and two aerosol modules used in this study. Since the AGCMs have been well documented (Roeckner et al., 2003; Collins et al., 2004; Wan et al., 2006), only the main features are mentioned here. In contrast, the aerosol module LIAM has not been reported in any publication in English, therefore a detailed description is provided here by contrasting it with the HAM module. A summary of the model information is presented in Tables 1 and 2 .

\subsection{Meteorology and tracer transport}

The GAMIL model has a finite-difference dynamical core using the pressure-based sigma coordinate in the vertical. The horizontal grid coincides with the Gaussian grid in the middle and low latitudes, while in the high latitudes lower meridional resolution is adopted so as to effectively enlarge 
Table 2. Summary of the main components of the two aerosol modules used in this study.

\begin{tabular}{|c|c|c|}
\hline & LIAM & HAM \\
\hline \multicolumn{3}{|l|}{ Emission } \\
\hline SU, BC, POM & AEROCOM & AEROCOM \\
\hline SS & $\begin{array}{l}\text { Guelle et al. (2001), Smith and Harrison } \\
\text { (1998) and Gong (2003) }\end{array}$ & $\begin{array}{l}\text { Guelle et al. (2001), Smith and Harrison } \\
\text { (1998) and Monahan et al. (1986) }\end{array}$ \\
\hline DU & Zender et al. (2003) & Tegen et al. (2002) \\
\hline Sulfur chemistry & Barth et al. (2000) & Feichter et al. (1996) \\
\hline Gas oxidants & $\begin{array}{l}\text { IMAGE monthly mean output of } \mathrm{OH} \text {, } \\
\mathrm{NO}_{3}, \mathrm{HO}_{2}\end{array}$ & $\begin{array}{l}\text { MOZART monthly mean output of } \mathrm{OH} \\
\mathrm{H}_{2} \mathrm{O}_{2}, \mathrm{O}_{3}, \mathrm{HO}_{2}, \mathrm{NO}_{3}\end{array}$ \\
\hline Dry deposition & $\begin{array}{l}\text { Prescribed deposition velocities for gases } \\
\text { (Feichter et al., 1996); Zhang et al. (2001) } \\
\text { for aerosols }\end{array}$ & $\begin{array}{l}\text { Ganzeveld and Lelieveld } \\
\text { Ganzeveld et al. (1998) }\end{array}$ \\
\hline Sedimentation & $\begin{array}{l}\text { Seinfeld and Pandis (1998) with smaller } \\
\text { time step for large particles }\end{array}$ & $\begin{array}{l}\text { Seinfeld and Pandis (1998) with CFL sta- } \\
\text { bility limitation }\end{array}$ \\
\hline Wet deposition & $\begin{array}{l}\text { Similar to HAM, except for below-cloud } \\
\text { scavenging (see text) }\end{array}$ & $\begin{array}{l}\text { Herry's Law for gases in-cloud; below- } \\
\text { cloud scavenging and re-evaporation of } \\
\text { aerosols }\end{array}$ \\
\hline Aerosol microphysics & M7 module & M7 module \\
\hline Number of advective chemical tracers & 25 aerosols and 4 precursor gases & 25 aerosols and 3 precursor gases \\
\hline
\end{tabular}

the zonal grid size and reduce the computational instability in the Polar Regions. ECHAM5 and the Eulerian version of CAM3 both utilizes the spectral transform method for horizontal discretization. The grid-point calculations are performed on the Gaussian grid. The hybrid $p-\sigma$ vertical coordinate is used in both spectral models although the layers are located differently. In this study, simulations with the three models are conducted at similar spatial resolutions (see Table 1). Large-scale tracer transport in GAMIL and ECHAM5 is handled by the Flux Form Semi-Lagrangian (FFSL) algorithm (Lin and Rood, 1996). In CAM3 the semi-Lagrangian method proposed by Williamson and Rasch (1989) is employed. In order to ensure computational stability and at the same time preserve consistency between tracer transport and the continuity equation, GAMIL uses a relatively short time step $(4 \mathrm{~min})$ for the dynamical core and the transport scheme. The time steps used in CAM3 and ECHAM5 are 20 min and 30 min respectively.

The physics parameterizations in GAMIL originates from CAM2 and is therefore similar to CAM3. The major differences reside in the treatment of cloud condensed water. In GAMIL the cloud water and cloud ice concentrations are diagnosed and neither is transported, while in CAM3 they are both treated as advective tracers. Details of the physics parameterizations in the ECHAM5 model differ significantly from the CAM package. The main processes that are directly related to aerosol simulation include the cumulus convection, cloud, precipitation and the boundary layer processes. A brief comparison of the physics packages is presented in Table 1. For physical parameterizations, GAMIL and CAM3 use a time step of $20 \mathrm{~min}$, while ECHAM5 uses $30 \mathrm{~min}$ time step.

\subsection{The microphysics module M7}

As already mentioned in the introduction, both LIAM and HAM employ the M7 module (Vignati et al., 2004) for aerosol microphysics. The aerosol composition considered includes sulfate, black carbon, particulate organic matter, sea salt and dust. Different composition can be internally and/or externally mixed. The aerosol size spectrum is represented by a superposition of several log-normal modes, each of which has fixed mode boundaries and standard deviation and varying median radius. According to the particle size and solubility, the whole aerosol population is divided into seven modes shown in Table 3. Each individual mode is represented by its total particle number, and the mass of different compositions within this mode, which are all treated as advective tracers (Table 3 ).

The processes considered in the M7 module include nucleation, coagulation, sulfuric acid condensation and water uptake. We do not describe the details here and refer readers to the paper by Vignati et al. (2004). Note that there are two parameterizations available in M7 for calculating the formation of new sulfuric acid-water droplets: one by Vehkamaki (2002) and the other by Kulmala et al. (1998). Vignati et al. (2004) have pointed out that the Vehkamaki (2002) scheme is valid in broader ranges of temperatures and humidity, thus all simulations in this study are conducted with the Vehkamaki (2002) parameterization. 
Table 3. The log-normal modes in the M7 module and the related sources and sinks of aerosol mass and particle number. $r_{d}$ stands for the dry radius of the aerosol particle; $\sigma$ denotes the geometric standard deviation of the size distribution function. " $N$ " and " $M$ " in the third column stand for the number and mass concentrations, respectively. Their subscripts indicate the corresponding mode. The superscript of " $M$ " indicate the composition. Small circles indicate that a certain tracer is affected by a specific process.

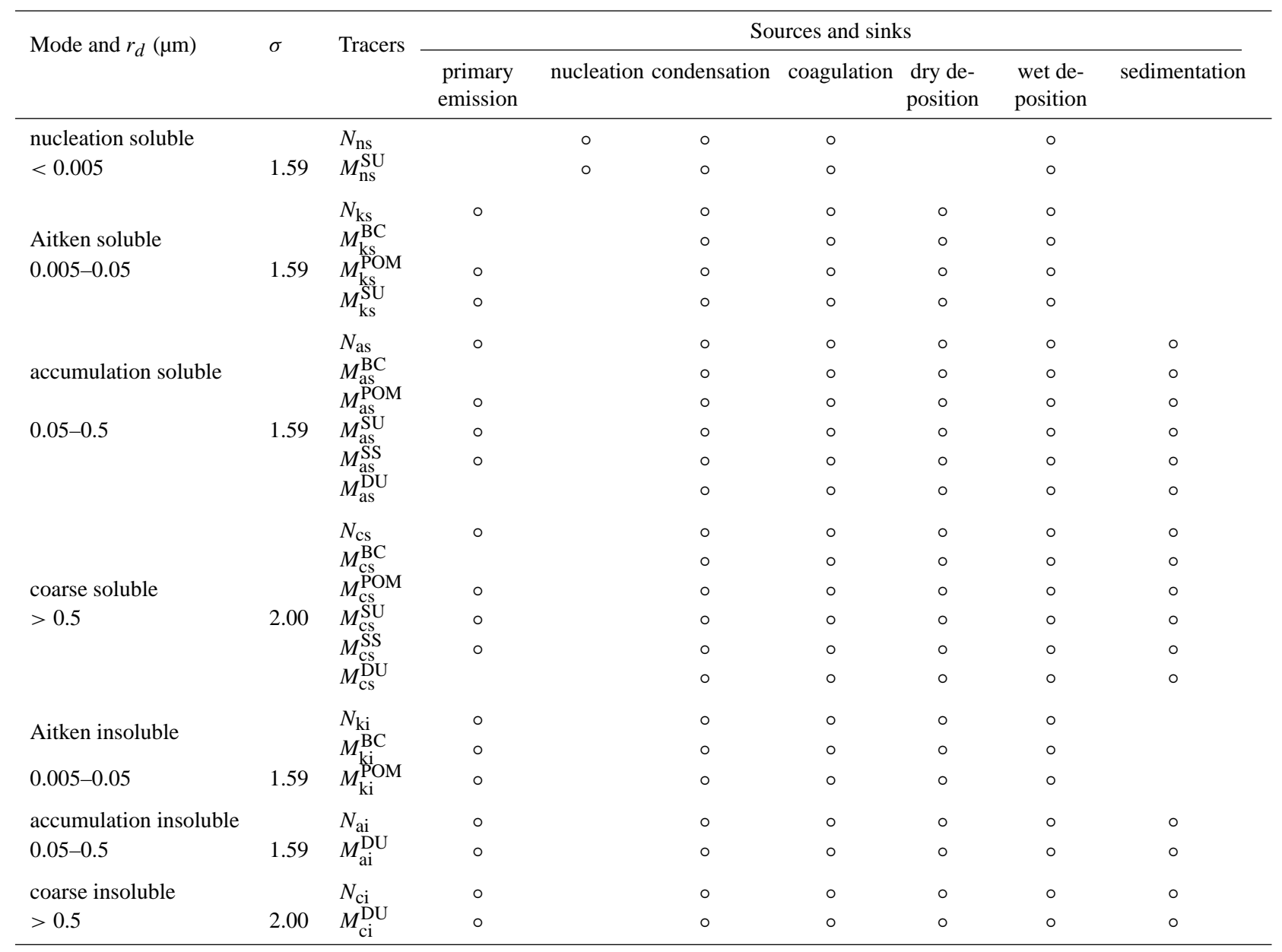

\subsection{Chemistry}

For an aerosol-climate model, it would be advantageous to have complex gas chemistry within the model system so as to allow for full interactions between the gas oxidants and the aerosols. However, this would lead to a significant increase in the required computational resources. In this study only the sulfur chemistry is interactively simulated.

The LIAM and HAM aerosol modules use the sulfur chemistry schemes proposed by Barth et al. (2000) and Feichter et al. (1996), respectively. Both schemes have considered the gas phase oxidation of dimethyl sulfide (DMS) and sulfur dioxide $\left(\mathrm{SO}_{2}\right)$, reaction of DMS with nitrate radicals $\left(\mathrm{NO}_{3}\right)$, as well as aqueous phase oxidation of $\mathrm{SO}_{2}$ by $\mathrm{H}_{2} \mathrm{O}_{2}$ and $\mathrm{O}_{3}$, although the reaction rate constants are slightly different. The mixing ratio of DMS, $\mathrm{SO}_{2}$ and sulfate $\left(\mathrm{SO}_{4}^{2-}\right)$ are prognostic variables in both modules. The mixing ratio of $\mathrm{H}_{2} \mathrm{O}_{2}$ is also predicted in LIAM but not in HAM.
Sulfuric acid gas $\left(\mathrm{H}_{2} \mathrm{SO}_{4}\right)$ produced by gas phase chemistry can either condense on existing particles or form new particles through particle nucleation. These two processes are handled in the M7 module introduced above. Sulfate produced in the aqueous chemistry is distributed to particles of the soluble accumulation mode and coarse mode according to the respective number concentration (Stier et al., 2005). This calculation is done in the sulfur chemistry scheme.

As for the other related oxidants, $\mathrm{OH}, \mathrm{O}_{3}, \mathrm{NO}_{3}$ and $\mathrm{HO}_{2}$ concentrations needed in LIAM are prescribed using threedimensional monthly means obtained from the Intermediate Model of Global Evolution of Species (IMAGES, Müller and Brasseur, 1995). In the HAM module, $\mathrm{OH}, \mathrm{H}_{2} \mathrm{O}_{2}, \mathrm{NO}_{2}$ and $\mathrm{O}_{3}$ concentrations are prescribed using monthly means given by the comprehensive Model of Ozone And Related Tracers (MOZART, Horowitz et al., 2003). 
It is worth noting that the $\mathrm{NO}_{3}$ concentration in the HAM module is not prescribed but calculated assuming a steady state between the production terms (i.e. depletion of $\mathrm{N}_{2} \mathrm{O}_{5}$ ) and loss terms (reacts with $\mathrm{NO}_{2}$ and DMS) (Feichter et al., 1996). Furthermore, the methane sulfuric acid (MSA) produced from the oxidation of DMS is assumed to occur as sulfuric acid in HAM. In the LIAM package the further conversion of MSA is ignored.

\subsection{Emission}

Global emission information is needed as an external forcing for the simulated aerosol composition and for precursor gases. In the present study we follow the experiment specifications of the Aerosol inter-Comparison project AeroCom (http://nansen.ipsl.jussieu.fr/AEROCOM/).

Due to the fact that no recommendation has been made for oxidant fields (Dentener et al., 2006), different data sets are used in the LIAM and HAM modules as already described in Sect. 2.3. In HAM the oceanic DMS emission is calculated online (Stier et al., 2005), while the terrestrial biogenic DMS emissions are prescribed following Pham et al. (1995). In LIAM both are prescribed using the data provided by AeroCom (Dentener et al., 2006). For $\mathrm{SO}_{2}$, sulfate, black carbon and the particulate organic matter, the emission rate and injection height are available from AeroCom (Dentener et al., 2006) at $1^{\circ} \times 1^{\circ}$ (longitude $\times$ latitude) resolution. The original data are mapped to the model grids using area-weighted interpolation. Dentener et al. (2006) have also specified the size distribution for the emissions. Since the recommended standard deviations differ from the values used in M7 module, the mode radius has been adapted to the (M7) model parameters (Stier et al., 2005). The partitioning of aerosol emissions among different modes is summarized in Table 4.

Sea salt particles are generated at the ocean's surface by the bursting of entrained air bubbles induced by wind stress (Monahan et al., 1986). Experimental investigations have indicated that the injection of sea salt into the atmosphere depends strongly on the meteorological conditions at the sea surface (Gong et al., 1997). In numerical models, generation of sea salt particles is usually parameterized by empirical functions of the droplet size and the 10-m wind speed. Previous studies (e.g., Guelle et al., 2001) have shown that the scheme of Monahan et al. (1986) works well for particle radius below $4 \mu \mathrm{m}$, and the formulation of Smith and Harrison (1998) is most appropriate for particles larger than $4 \mu \mathrm{m}$. In the HAM module, the two source functions are merged smoothly within the size range of $2-4 \mu \mathrm{m}$, and fitted into the accumulation mode and coarse mode. In LIAM, the Smith and Harrison (1998) scheme is used for particles larger than $4 \mu \mathrm{m}$, the Monahan et al. (1986) scheme is used for the size range $0.2-4 \mu \mathrm{m}$, and the modification by Gong (2003) is employed for radii below $0.2 \mu \mathrm{m}$ to avoid the overestimates resulting from the Monahan et al. (1986) scheme.
Emission of dust is computed online in both aerosol modules according to the surface land types, 10-m wind and other atmospheric boundary layer properties. HAM uses the scheme proposed by Tegen and Lacis (1996), calculates the emission flux from 192 internal size classes, then fit them into the insoluble accumulation and coarse modes; in LIAM, the modal algorithm of Zender et al. (2003) is adapted by mapping the original source size distribution into the insoluble accumulation and coarse modes, resulting in about $96 \%$ of the emitted particle mass attributed to the coarse mode.

\subsection{Dry deposition}

Dry deposition is an important sink of aerosols and trace gases in the atmosphere. There are two main contributing mechanisms: the turbulent dry deposition happening near the Earth's surface and the gravitational settlement (i.e. sedimentation) which occurs within the whole vertical domain of the atmosphere. Both mechanisms can be described by a general formulation

$F_{i}=C_{i} \rho_{a} V_{i}$,

which indicates that for a particular species $i$, the dry deposition flux $F_{i}$ is proportional to the species' density $C_{i} \rho_{a}$ and the deposition velocity $V_{i}$. The central task of the deposition parameterization is to find out an appropriate expression for $V_{i}$.

The removal rate of aerosols from the atmosphere via dry deposition is closely related to the size of the particles. In many previous studies, especially those using the bulk method, the deposition velocity is usually linked to some prescribed (fixed) values of particle size. The modal approach adopted by the M7 module allows for varying size spectra, therefore both in HAM and in LIAM, the mode radius derived from the predicted number and mass concentrations is used to represent the particle size of aerosols. Moreover, due to the fact that the mass and number concentrations are treated as separate tracers, the size spectra in the two aerosol modules are interactively affected by the deposition processes.

As will be demonstrated later, some evident differences have been detected in the simulation results from the three aerosol-climate model systems used in this study, which is attributable to the deposition processes. In order to facilitate later analysis, crucial details of the parameterization schemes are summarized and compared below.

\subsubsection{Turbulence dry deposition}

The turbulent dry deposition affects both the trace gases and aerosols. The deposition velocity is usually computed using the big leaf approach as $V_{\text {Dep }}=R^{-1}$ with $R$ being the parameterized resistance. 
Table 4. Partitioning of the aerosol emissions among different modes. The small circles in the last two rows denote online calculation.

\begin{tabular}{|c|c|c|c|c|c|c|c|}
\hline \multirow{2}{*}{ Composition } & \multirow{2}{*}{ Emission type } & \multicolumn{3}{|c|}{ Insoluble modes } & \multicolumn{3}{|c|}{ Soluble modes } \\
\hline & & Aitken & accumulation & coarse & Aitken & accumulation & coarse \\
\hline \multirow{3}{*}{ Black carbon } & bio-fuel & $100 \%$ & & & & & \\
\hline & fossil fuel & $100 \%$ & & & & & \\
\hline & biomass burning & $100 \%$ & & & & & \\
\hline \multirow{4}{*}{$\begin{array}{l}\text { Particulate } \\
\text { organic } \\
\text { matter }\end{array}$} & fossil fuel & $100 \%$ & & & & & \\
\hline & bio-fuel & $35 \%$ & & & $65 \%$ & & \\
\hline & biogenic & $35 \%$ & & & $32.5 \%$ & $32.5 \%$ & \\
\hline & biomass burning & $35 \%$ & & & $65 \%$ & & \\
\hline \multirow{9}{*}{ Sulfate } & off-road & & & & $50 \%$ & $50 \%$ & \\
\hline & road transport & & & & $50 \%$ & $50 \%$ & \\
\hline & domestic & & & & $50 \%$ & $50 \%$ & \\
\hline & international shipping & & & & $50 \%$ & $50 \%$ & \\
\hline & industry & & & & & $50 \%$ & $50 \%$ \\
\hline & power plant & & & & & $50 \%$ & $50 \%$ \\
\hline & biomass burning & & & & $50 \%$ & $50 \%$ & \\
\hline & continuous volcano & & & & $50 \%$ & $50 \%$ & \\
\hline & eruptive volcano & & & & $50 \%$ & $50 \%$ & \\
\hline Sea salt & online calculation & & & & & $\circ$ & $\circ$ \\
\hline Dust & online calculation & & $\circ$ & $\circ$ & & & \\
\hline
\end{tabular}

For gaseous tracers, the scheme of Ganzeveld and Lelieveld (1995) and Ganzeveld et al. (1998) is used in the HAM module. The first contributor to resistance $R$ is the aerodynamic resistance $R_{a}$ determined by atmospheric stability and friction velocity (calculated by the boundary layer scheme in the GCM), which are in turn functions of the vertical gradient of temperature and momentum near the Earth's surface; the second contributor, quasi-laminar boundary layer resistance $R_{b}$, is determined by kinematic viscosity of air (a function of temperature), friction velocity, and some empirical parameters. The third contributor, surface resistance $R_{S}$, is prescribed for most trace gases, with the only exception that the $\mathrm{SO}_{2}$ soil resistance is computed from soil $\mathrm{pH}$, relative humidity, surface temperature, and the canopy resistance (Stier et al., 2005). The total resistance is then given as the sum of these three contributors.

This online calculation provides a consistent deposition velocity in the sense that it changes instantaneously with model meteorology and the underlying surface characteristics. On the other hand, the study by Feichter et al. (1996) showed that the dry deposition velocities prescribed by Langner and Rodhe (1991) for different chemical constituents and surface types work well in simulation of the tropospheric sulfur cycle. In the LIAM model we follow the work of Feichter et al. (1996) and use the same prescribed values for gaseous sulfur species and precursors.

As for aerosol particles, both the HAM and LIAM modules use the big leaf method with $R=R_{a}+R_{s}$. A detailed description of the resistance calculation used in HAM can be found in Kerkweg et al. (2006). The parameterization scheme for aerosol particles used in LIAM follows the work of Zhang et al. (2001). Since the actual formulas are rather lengthy, we only provide a brief summary here:

- The aerodynamic resistance $R_{a}$ in both modules are calculated in the same way as for the trace gases in HAM.

- The surface resistance $R_{s}$ depends on the particle size and the surface collection efficiency. The latter is determined by the atmospheric conditions and the properties of the Earth's surface.

- When calculating the surface collection efficiency, both modules have considered the Brownian diffusion, impaction and interception, of which control variables are the Schmidt number, the Stokes number and particle radius, respectively. On the other hand, HAM and LIAM differ in the formulation details and in the empirical parameters.

- Regarding particle radius, the mass mean and number median radius of each mode are used for calculating $R_{S}$ of aerosol mass and number concentrations, respectively.

- The dry deposition flux of nucleation mode particles is very small and thus ignored in both modules. 


\subsubsection{Sedimentation}

Sedimentation affects on aerosol particles throughout the whole vertical domain of the model atmosphere. The sedimentation velocities in HAM and LIAM are both calculated based on the Stokes theory (see, e.g., p. 465 in Seinfeld and Pandis, 1998), which describes the dynamical movement of a single particle. Since the modal representation in M7 each mode includes particles of different sizes, the mass (number) median radius is used in the calculation of sedimentation velocity of aerosol mass (number), and then the Slinn correction (Slinn and Slinn, 1980) is used to get the sedimentation velocity of a log-normal aerosol size distribution with a given standard deviation.

To avoid violation of the Courant-Friedrich-Lewy stability criterion, the sedimentation velocity is limited to $V<\frac{\Delta z}{\Delta t}$ in HAM, where $\Delta z$ is the layer thickness (in meters) and $\Delta t$ is the model time step (Stier et al., 2005). In LIAM, we take two successive time steps $(\Delta t / 2$ each) when updating the soluble and insoluble coarse modes, so as to preserve computational stability and achieve higher accuracy.

It is worth noting that although the mass concentrations of different composition in the same soluble mode are treated as separate tracers, they are assumed to be internally mixed. For each mode, a single mass median radius is derived from the number concentration and the total mass concentration, and used subsequently in the calculation of turbulent/sedimentation velocity. Therefore the mass concentrations in each mode - as different tracers - share the same deposition velocities.

\subsection{Wet deposition}

Wet deposition parameterization simulates the loss of trace gases and aerosols caused by cloud formation (i.e. the incloud scavenging) and precipitation (the so-called belowcloud scavenging), as well as release of these tracers back into the atmosphere due to the evaporation of rain droplets. All these three processes are considered both in HAM and in LIAM. The impact on gases and aerosols are treated differently. For gases, the solubility in cloud water and removal by precipitation are calculated according to the Henry's law (see, e.g., Seinfeld and Pandis, 1998). As for aerosols, the fraction of the total amount that is involved in cloud formation is prescribed according to the size and solubility of each aerosol type (see Table 3 in Stier et al., 2005). In reality the in-cloud loss is caused by the activation process which converts aerosol particles into cloud droplets. However, the parameterization of activation is not explicitly included in the model versions used in the present study. The precipitation formation rate is further used to convert activated aerosols to precipitation phase. Therefore the resulting in-cloud aerosol loss depends strongly on the strength and distribution of precipitation predicted by the hosting GCM. The formulation of the in-cloud scavenging in LIAM is essentially the same as in
HAM, although the parameters have been slightly scaled so as to provide reasonable deposition rates (according to simulated total wet deposition flux and aerosol lifetime).

Aerosols below precipitating clouds are subject to removal from the atmosphere by rain droplets. The resulting concentration tendency is assumed to be proportional to the precipitation rate and area, and the collection efficiency. The size-dependent collection efficiency for rain and snow follows Seinfeld and Pandis (1998). LIAM and HAM only differ slightly in the calculation of precipitation area.

\section{Model setup and simulated global mean mass budget and lifetime}

Climate simulations are conducted using the three aerosolclimate models mentioned above, each proceeding 3 model years. The meteorological fields are initialized using the output of a long-term simulation with the same model but without aerosols. The sea surface temperature and sea ice concentration (as external forcing) are the 1979-2001 multi-year mean monthly average. The initial aerosol concentrations are zero. Typically the aerosol burden increases to its normal average values within less than one model year. Thus we calculate the diagnostics based on the monthly average output of the last two model years of the simulations.

Before going into details of the simulated aerosol size distributions, we first present an overall picture of the aerosol life cycles in the three models by showing in Tables 5 and 6 the globally averaged annual mean mass budget and life times of the five aerosol types. The corresponding values in some other models mentioned in Liu et al. (2005) are presented in the rightmost columns for comparison. To facilitate analysis, the precursors of sulfate are also included.

The first message from the two tables is that regarding global mean burdens, results from the three models are quite similar for all the five aerosol types. The ECHAM5-HAM results shown here at T42L19 resolution are also very close to the T63L31 nudged simulation in Stier et al. $(2005)^{2}$. On the other hand, discrepancies between models exist in the contribution from specific process. For sulfate and carbonous aerosols, the differences between GAMIL-LIAM and CAM3-LIAM are evidently much smaller than between either of them and ECHAM5-HAM. This suggests that global and annual mean budgets of these species are highly sensitive to the parameterization schemes of the aerosol-related physical (e.g. transport and deposition) and chemical processes.

The sulfate aerosol burdens simulated by the LIAM and HAM modules turn out to have similar dynamical equilibriums which result from sulfur cycles with significantly different strengths. This can been seen from the different lifetimes (see the " $\mathrm{SO}_{4}^{2-}$ particle" part of Table 5). Both the source and

\footnotetext{
${ }^{2}$ An exception here is dust, for which it is already known that the emission flux in nudged simulations is significantly smaller than in climatological runs (Timmreck and Schulz, 2004).
} 
Table 5. Annual mean global sulfur budget obtained in this study and from the literature.

\begin{tabular}{|c|c|c|c|c|}
\hline & $\begin{array}{l}\text { GAMIL } \\
\text {-LIAM }\end{array}$ & $\begin{array}{l}\text { CAM3 } \\
\text {-LIAM }\end{array}$ & $\begin{array}{l}\text { ECHAM5 } \\
\text {-HAM }\end{array}$ & $\begin{array}{c}\text { from } \\
\text { Liu et al. (2005) }\end{array}$ \\
\hline $\begin{array}{l}\quad \mathbf{S O}_{4}^{2-} \text { particle } \\
\text { Burden }(\mathrm{Tg} \mathrm{S})\end{array}$ & 0.72 & 0.75 & 0.75 & $0.53-1.07$ \\
\hline $\begin{array}{l}\text { Sources }\left(\mathrm{Tg} \mathrm{S} \mathrm{yr}^{-1}\right) \quad \text { Total } \\
\text { Primary emissions } \\
\text { Nucleation } \\
\mathrm{H}_{2} \mathrm{SO}_{4} \text { condensation } \\
\text { Aqueous oxidation }\end{array}$ & $\begin{array}{c}59.2 \\
1.76 \\
0.044 \\
6.1 \\
51.3\end{array}$ & $\begin{array}{c}61.7 \\
1.77 \\
0.046 \\
7.4 \\
52.5\end{array}$ & $\begin{array}{c}75.6 \\
1.78 \\
0.044 \\
25.0 \\
48.8\end{array}$ & $\begin{array}{c}6.1-22.0 \\
24.5-57.8\end{array}$ \\
\hline $\begin{array}{l}\text { Sinks }\left(\mathrm{Tg} \mathrm{S} \mathrm{yr}^{-1}\right) \\
\text { Total } \\
\text { Dry deposition } \\
\text { Sedimentation } \\
\text { Wet deposition } \\
\text { Lifetime (days) }\end{array}$ & $\begin{array}{c}60.9 \\
2.8 \\
1.3 \\
56.8 \\
4.4\end{array}$ & $\begin{array}{c}62.4 \\
2.9 \\
1.1 \\
58.4 \\
4.5\end{array}$ & $\begin{array}{c}75.8 \\
2.5 \\
1.7 \\
71.6 \\
3.6\end{array}$ & $\begin{array}{c}34.7-61.1 \\
3.9-6.8\end{array}$ \\
\hline $\begin{array}{l}\text { Sulfuric acid gas } \\
\text { Burden }(\mathrm{Tg} S)\end{array}$ & 0.00040 & 0.00052 & 0.00060 & \\
\hline $\begin{array}{l}\text { Sources }\left(\mathrm{Tg} \mathrm{S} \mathrm{yr}^{-1}\right) \\
\text { Total } \\
\mathrm{SO}_{2}+\mathrm{OH} \quad \text { (gas) } \\
\mathrm{DMS}+\mathrm{OH} \text { (gas) }\end{array}$ & $\begin{array}{c}6.2 \\
6.2 \\
-\end{array}$ & $\begin{array}{c}7.4 \\
7.4 \\
-\end{array}$ & $\begin{array}{c}25.1 \\
22.5 \\
2.6\end{array}$ & \\
\hline $\begin{array}{l}\text { Sinks }\left(\mathrm{Tg} \mathrm{S} \mathrm{yr}^{-1}\right) \\
\text { Total } \\
\text { Nucleation } \\
\mathrm{H}_{2} \mathrm{SO}_{4} \text { condensation } \\
\text { Dry deposition } \\
\text { Lifetime (days) }\end{array}$ & $\begin{array}{c}6.1 \\
0.044 \\
6.1 \\
0.0006 \\
0.023\end{array}$ & $\begin{array}{c}7.3 \\
0.046 \\
7.3 \\
0.0014 \\
0.030\end{array}$ & $\begin{array}{c}25.1 \\
0.044 \\
25.0 \\
0.009 \\
0.010\end{array}$ & \\
\hline $\begin{array}{c}\mathbf{S O}_{2} \\
\text { Burden }(\operatorname{Tg~S})\end{array}$ & 0.34 & 0.35 & 0.58 & $0.2-0.69$ \\
\hline $\begin{array}{l}\text { Sources }\left(\mathrm{Tg} \mathrm{S} \mathrm{yr}^{-1}\right) \\
\text { Total } \\
\text { Emissions } \\
\text { DMS + OH (gas) } \\
\text { DMS + } \mathrm{NO}_{3} \text { (gas) }\end{array}$ & $\begin{array}{c}84.9 \\
68.7 \\
12.0 \\
4.2\end{array}$ & $\begin{array}{c}85.2 \\
68.9 \\
12.0 \\
4.3\end{array}$ & $\begin{array}{c}94.4 \\
71.7 \\
17.5 \\
5.2\end{array}$ & \} 10.0-25.6 \\
\hline $\begin{array}{l}\text { Sinks }\left(\mathrm{Tg} \mathrm{S}^{-1}\right) \\
\text { Total } \\
\mathrm{SO}_{2}+\mathrm{OH} \text { (gas) } \\
\text { Sink in aqueous chem. } \\
\text { Dry deposition } \\
\text { Wet deposition } \\
\text { Lifetime (days) }\end{array}$ & $\begin{array}{c}84.9 \\
6.2 \\
51.3 \\
26.8 \\
0.61 \\
1.0\end{array}$ & $\begin{array}{c}85.3 \\
7.4 \\
52.3 \\
24.5 \\
0.65 \\
0.95\end{array}$ & $\begin{array}{l}92.6 \\
22.5 \\
48.8 \\
16.8 \\
4.5 \\
2.2\end{array}$ & $\begin{array}{c}6.1-22.0 \\
24.5-57.8 \\
16.0-55.0 \\
0-19.9 \\
0.6-2.6\end{array}$ \\
\hline $\begin{array}{c}\text { DMS } \\
\text { Burden }(\mathrm{Tg} \mathrm{S})\end{array}$ & 0.093 & 0.087 & 0.085 & $0.02-0.15$ \\
\hline $\begin{array}{l}\text { Source }\left(\mathrm{Tg} \mathrm{S} \mathrm{yr}^{-1}\right) \\
\text { Emissions }\end{array}$ & 18.2 & 18.2 & 25.4 & $10.7-26.1$ \\
\hline $\begin{array}{l}\left.\text { Sinks (Tg S yr }{ }^{-1}\right) \\
\mathrm{DMS}+\mathrm{OH} \text { (gas) } \\
\text { DMS + } \mathrm{NO}_{3} \text { (gas) } \\
\text { Lifetime (days) }\end{array}$ & $\begin{array}{l}14.1 \\
4.2 \\
1.9\end{array}$ & $\begin{array}{l}14.0 \\
4.3 \\
1.7\end{array}$ & $\begin{array}{c}17.5 \\
5.2 \\
1.3\end{array}$ & $0.5-3.0$ \\
\hline
\end{tabular}


loss rates in ECHAM5-HAM are more than 30\% larger than in the other two models, which can be attributed mainly to the stronger $\mathrm{H}_{2} \mathrm{SO}_{4}$ condensation (source) and stronger wet deposition (sink). Compared to the other models results collected in Liu et al. (2005), it seems that the condensation rate in ECHAM5-HAM is higher than the other models, while the values in the two models using LIAM are among the lowest (see the rightmost column in Table 5).

The strong condensation in ECHAM5-HAM is directly related to the high $\mathrm{H}_{2} \mathrm{SO}_{4}$ production from the oxidation of $\mathrm{SO}_{2}$ by $\mathrm{OH}$. According to the numbers listed in Table 5 and the comparison between the parameterization schemes in the HAM and LIAM modules, there can be two immediate reasons for the different $\mathrm{H}_{2} \mathrm{SO}_{4}$ productions: 1) stronger $\mathrm{SO}_{2}$ production from DMS and weaker dry deposition of the $\mathrm{SO}_{2}$ gas in ECHAM5-HAM, which may have lead to higher $\mathrm{SO}_{2}$ burden; 2) differences in the concentrations of the oxidants which are prescribed using different data sets.

In order to quantify the contribution from these factors, several sensitivity tests are performed using ECHAM5HAM:

- Experiment Ia, in which the turbulent dry deposition in HAM is replaced by the parameterization in LIAM. As expected, the dry deposition rate in ECHAM5-HAM is enhanced to a level similar to the other two models, the oxidation of $\mathrm{SO}_{2}$ is weakened, and the $\mathrm{H}_{2} \mathrm{SO}_{4}$ condensation rate is reduced from 25.0 to $21.9 \mathrm{Tg} \mathrm{S} \mathrm{yr}^{-1}$ (by $12.4 \%$ ). Understandably, the SU burden is also decreased.

- Experiment Ib, in which the DMS emission is scaled down to the global and annual mean prescribed by AeroCom (i.e., from 25.4 to 18.2 , see Table 5). This leads to reduced $\mathrm{SO}_{2}$ production, and eventually a $6.4 \%$ decrease of the condensation of $\mathrm{H}_{2} \mathrm{SO}_{4}$ (i.e., from 25.0 to 23.4). Like in the first experiment, the SU burden is also decreased.

- Experiment II, in which the oxidant concentrations are prescribed using the IMAGES model data as in the other two models. In this simulation more $\mathrm{SO}_{2}$ are consumed in the aqueous phase oxidation and less in the gas phase reactions, but the total amount remains almost unchanged. Although the condensation rate is reduced to $22.5 \mathrm{Tg} \mathrm{S} \mathrm{yr}^{-1}$, there is no significant change in either the burden or the lifetime of the SU aerosol.

- Experiment III, in which the three modifications above are combined in one simulation to take into account the interaction and nonlinearity. It turns out that in terms of $\mathrm{H}_{2} \mathrm{SO}_{4}$ condensation rate, the decrease is close to the sum of the changes in the previous three experiments. Although reduced to $17.6 \mathrm{Tg} \mathrm{S} \mathrm{yr}^{-1}$, it is still more than twice the values in the other two models.
These tests suggest that the large differences of the $\mathrm{H}_{2} \mathrm{SO}_{4}$ production in the three models must have resulted from other reasons than the dry deposition of $\mathrm{SO}_{2}$, DMS emission, and the oxidants. Possibilities include the chemical reaction schemes, the related meteorological conditions (such as cloud liquid content and cloud cover), and the sequence of calculating the various processes (including the gas/aqueous phase reactions and deposition processes) within the sulfur chemistry scheme. Which of these plays the major role is not yet clear. We will leave the further analysis in the future research.

The dramatic differences in the $\mathrm{H}_{2} \mathrm{SO}_{4}$ condensation rate may lead to significant discrepancies in the simulated size distributions. So as to investigate the impact, another sensitivity experiment, referred to as "EXP-60P", is performed with ECHAM5-HAM. Here we manually reduced the $\mathrm{H}_{2} \mathrm{SO}_{4}$ production to $60 \%$ of the original values, and apply the same scaling factor to the wet deposition coefficients. The simultaneous reduction of the source and sink of SU does not affect the burden, but increases the SU lifetime to 4.1 days. Other results from this simulation will be discussed in the next section.

Regarding BC and POM, the burdens and total sources and sinks strengths are very similar in the three models (Table 6). The values are also well within the range given by previous studies (see the last column in Table 6) and by the AeroCom models. The main difference between the three models is the relative contribution from the wet and dry deposition to the reduction rate.

Sea salt has a relatively simple life cycle compared to the other aerosol types, and is more sensitive to the 10-m wind which determines its emission process. The differences in our simulations (Table 6) can be regarded as indication of differences in the emission schemes in use and the discrepancies in model meteorology in the near surface layers. Further details are presented in the next section. As for dust, the emission rate depends additionally on the underlying surface characteristics (which are typically prescribed using external data), as well as on the parameterization scheme of mobilization. Since these data and schemes are highly empirical and consequently associated with large uncertainties, we list the dust budget in Table 6 for completeness but do not make further quantitative comparison.

\section{Global distribution of aerosol number concentration}

In this section we present and inter-compare the simulated annual mean number concentrations of all the seven modes resolved by the $\mathrm{M} 7$ module. In the figures the concentration is given as number of particles per cubic centimeter at the standard atmospheric state (1013.25 hPa, 273.15 K). 
Table 6. Annual mean global BC, POM, SS, DU budgets obtained in this study and from the literature.

\begin{tabular}{|c|c|c|c|c|}
\hline & $\begin{array}{l}\text { GAMIL } \\
\text {-LIAM }\end{array}$ & $\begin{array}{l}\text { CAM3 } \\
\text {-LIAM }\end{array}$ & $\begin{array}{c}\text { ECHAM5 } \\
\text {-HAM }\end{array}$ & $\begin{array}{c}\text { from } \\
\text { Liu et al. (2005) }\end{array}$ \\
\hline \multicolumn{5}{|l|}{ Black carbon } \\
\hline Burden (Tg) & 0.13 & 0.13 & 0.11 & \multirow[t]{3}{*}{$0.12-0.29$} \\
\hline \multicolumn{4}{|l|}{ Sources $\left(\mathrm{Tg} \mathrm{yr}^{-1}\right)$} & \\
\hline Emissions & 7.7 & 7.7 & 7.7 & \\
\hline \multicolumn{5}{|l|}{ Sinks $\left(\operatorname{Tg~yr}^{-1}\right)$} \\
\hline Total & 7.6 & 7.6 & 7.8 & \multirow{3}{*}{\} $1.6-4.6$} \\
\hline Dry deposition & 0.87 & 1.1 & 0.71 & \\
\hline Sedimentation & 0.02 & 0.02 & 0.03 & \\
\hline Wet deposition & 6.7 & 6.2 & 7.1 & $7.8-13.7$ \\
\hline Lifetime (days) & 6.2 & 6.2 & 5.2 & $3.3-8.4$ \\
\hline \multicolumn{5}{|l|}{ POM } \\
\hline Burden (Tg) & 1.2 & 1.1 & 0.93 & \multirow[t]{2}{*}{$0.95-1.8$} \\
\hline \multicolumn{4}{|l|}{ Sources $\left(\mathrm{Tg} \mathrm{yr}^{-1}\right)$} & \\
\hline Emissions & 65.8 & 65.8 & 66.6 & \\
\hline \multicolumn{5}{|l|}{ 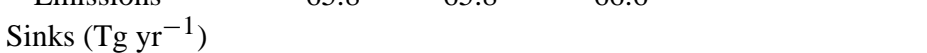 } \\
\hline Total & 65.9 & 65.8 & 66.0 & \multirow{3}{*}{ \}11.3-29.8 } \\
\hline Dry deposition & 5.8 & 7.2 & 5.7 & \\
\hline Sedimentation & 0.11 & 0.10 & 0.21 & \\
\hline Wet deposition & 60.0 & 58.5 & 60.1 & $60.1-113.3$ \\
\hline Lifetime (days) & 6.3 & 6.2 & 5.1 & $3.2-6.4$ \\
\hline \multicolumn{5}{|l|}{ Sea salt } \\
\hline Burden $(\mathrm{Tg})$ & 12.9 & 14.9 & 11.3 & $3.4-12.0$ \\
\hline \multicolumn{5}{|l|}{ Sources $\left(\operatorname{Tg~yr}^{-1}\right)$} \\
\hline Emissions & 8366 & 11785 & 6615 & $1010-8076$ \\
\hline \multicolumn{5}{|l|}{ Sinks $\left(\mathrm{Tg} \mathrm{yr}^{-1}\right)$} \\
\hline Total & 8389 & 11845 & 6650 & \multirow{3}{*}{$3940-7450$} \\
\hline Dry deposition & 1432 & 2586 & 1680 & \\
\hline Sedimentation & 3730 & 4454 & 1800 & \\
\hline Wet deposition & 3227 & 4805 & 3170 & $74-2436$ \\
\hline Lifetime (days) & 0.57 & 0.46 & 0.62 & $0.19-0.99$ \\
\hline \multicolumn{5}{|l|}{ Dust } \\
\hline Burden $(\mathrm{Tg})$ & 13.6 & 13.9 & 16.8 & $4.3-35.9$ \\
\hline \multicolumn{5}{|l|}{ Sources $\left(\mathrm{Tg} \mathrm{yr}^{-1}\right)$} \\
\hline Emissions & 1052 & 1201 & 1378 & $820-5102$ \\
\hline \multicolumn{5}{|l|}{ Sinks $\left(\mathrm{Tg} \mathrm{yr}^{-1}\right)$} \\
\hline Total & 1075 & 1210 & 1389 & \multirow{3}{*}{ \}486-4080 } \\
\hline Dry deposition & 36.1 & 61 & 120 & \\
\hline Sedimentation & 325 & 437 & 550 & \\
\hline Wet deposition & 714 & 712 & 719 & $183-1027$ \\
\hline Lifetime (days) & 4.7 & 4.2 & 4.4 & $1.9-7.1$ \\
\hline
\end{tabular}

\subsection{Nucleation mode and soluble Aitken mode}

The first two rows in Fig. 1 display the zonal and annual mean number concentrations of the nucleation mode and the soluble Aitken mode simulated by the three models. In both LIAM and HAM, particles of the nucleation mode are generated exclusively from the neutral binary nucleation. Strong conversion of the sulfuric acid gas to particles results from high sulfuric acid concentration, high relative humidity and low temperature. Thus the upper troposphere is the most favorable region, as can be seen in the vertical cross sections (Fig. 1, first row). The soluble Aitken mode particles in M7 are internal mixtures of sulfate, black carbon and organic carbon. In the middle and upper troposphere, the most important source of Aitken mode particles is the condensation of sulfuric acid gas on nucleation mode particles. 

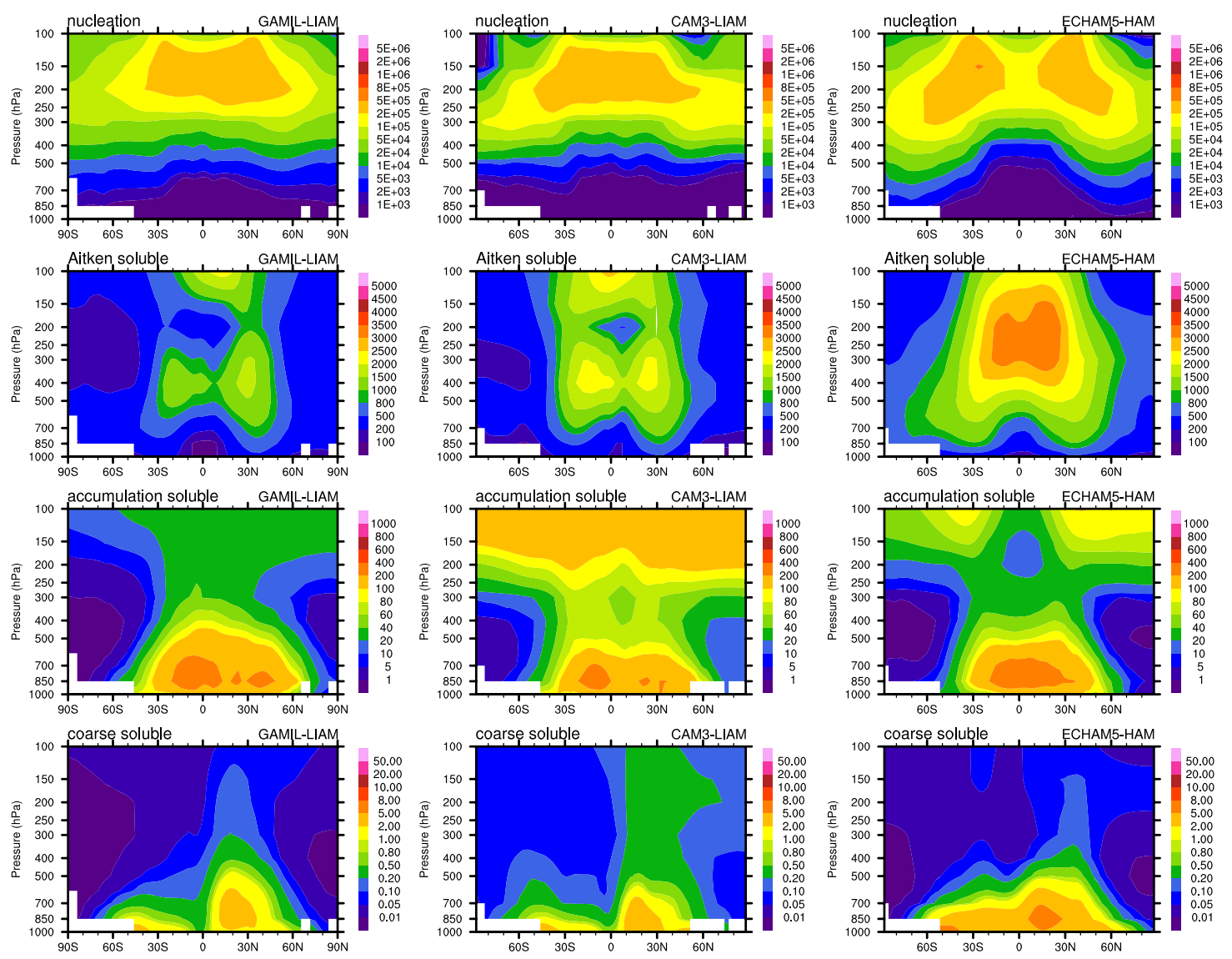

Fig. 1. Zonal and annual mean aerosol number concentrations of the four soluble modes (from top to bottom) simulated by GAMIL-LIAM (left column), CAM3-LIAM (middle column) and ECHAM5-HAM (right column). The unit is number of particles per cubic centimeter at the standard atmospheric state $(1013.25 \mathrm{hPa}, 273.15 \mathrm{~K})$.

Regarding the nucleation mode, the three model simulations agree reasonably well in the vertical distribution and the magnitude of the number concentration. This is consistent with the similar global and annual mean nucleation rates (see the first block of Table 5). The most evident difference is the higher concentrations near the tropical upper troposphere in the two models using LIAM. As for the soluble Aitken mode, all three models agree that the tropical regions are associated with relatively high concentrations, although the actual values differ significantly.

As mentioned in the previous section, the sensitivity experiment EXP-60P has been conducted with ECHAM5$\mathrm{HAM}$, in which the $\mathrm{H}_{2} \mathrm{SO}_{4}$ yields due to the oxidation of $\mathrm{SO}_{2}$ is scaled down to $60 \%$ of the original values. The consequence is that near the tropical upper troposphere the nucleation mode number concentration is increased due to slower growth of nucleation mode particles, and thus the Aitken mode number concentration is considerably decreased (Fig. 2, right column). In another experiment in which the $\mathrm{H}_{2} \mathrm{SO}_{4}$ yields in CAM3-LIAM are doubled, the Aitken mode number concentration increases and the pattern becomes much more similar to the ECHAM5-HAM result (Fig. 2, left column). These two experiments indicate that the condensation of $\mathrm{H}_{2} \mathrm{SO}_{4}$ plays a major role in the particle growth in the aforementioned region, and can lead to large discrepancies among models in the number concentrations of the nucleation and soluble Aitken modes.

Near the surface layers, nucleation mainly happens in the high-latitude continental areas. As expected, the high number concentrations in ECHAM5-HAM and GAMIL-LIAM are high over Antarctica and North Eurasia (first row in Fig. 3) are consistent with expectation. The lower concentration in GAMIL-LIAM over Greenland, Siberia and northwest part of North America is related to the warm bias in winter (not shown). In CAM3-LIAM, the high concentrations from $45^{\circ} \mathrm{N}$ are missing, probably also due to the temperature bias, since the 2-m temperature is typically associated with a positive bias of 2 to $12{ }^{\circ} \mathrm{C}^{3}$. The higher concentrations in ECHAM5-HAM seem partly attributable to the abundant

\footnotetext{
${ }^{3}$ Figure available from the CAM 3.0 Simulation Page: http://www.ccsm.ucar.edu/models/atm-cam/sims/cam3.0/ cam2_0_2_dev59/cam2_0_2_dev59-obs/set5_6/set5_DJF_TREFHT
} 

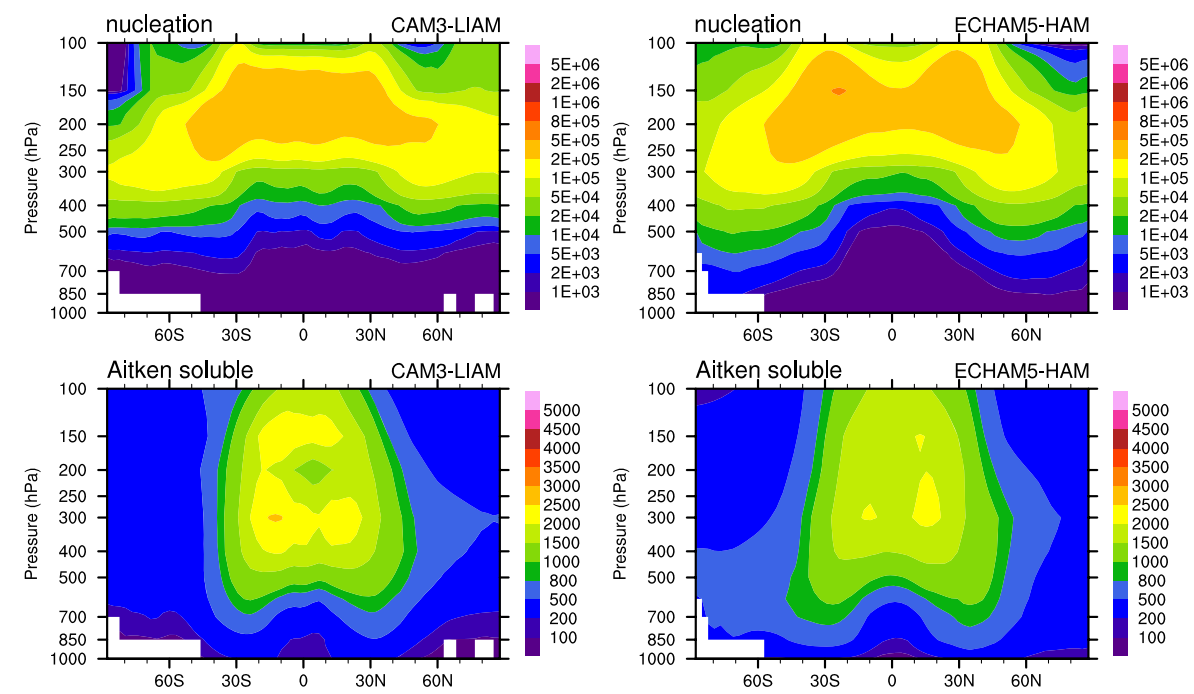

Fig. 2. Zonal and annual mean aerosol number concentrations of the nucleation mode (upper row) and Aitken soluble mode (bottom row) simulated by CAM3-LIAM (left colomn) and ECHAM5-HAM (right column) in sensitivity tests. The unit is number of particles per cubic centimeter at the standard atmospheric state $(1013.25 \mathrm{hPa}, 273.15 \mathrm{~K})$. In the CAM3-LIAM simulation the $\mathrm{H}_{2} \mathrm{SO}_{4}$ yields are doubled compared to the control experiment. In the ECHAM5-HAM simulation (referred to as "EXP-60P" in the text), both the $\mathrm{H}_{2} \mathrm{SO}_{4}$ yields and the wet deposition coefficients are scaled down to $60 \%$ of the original values.

$\mathrm{H}_{2} \mathrm{SO}_{4}$. In the EXP-60P simulation the nucleation mode concentration is generally lower from $40^{\circ}$ latitudes pole-ward, both over land and over the ocean (not shown).

The soluble Aitken mode particles near the Earth's surface mainly come from natural and anthropogenic emissions and aging of the insoluble particles. Aging itself is a physical process in LIAM and HAM, caused by condensation and the coagulation of insoluble aerosols with soluble particles. These processes, however, are closely related with the sulfur cycle. From the second row of Fig. 3 it is clear that ECHAM5-HAM produces more soluble Aitken mode particles. Over the mid-latitude continents in the Northern Hemisphere, the higher number concentrations are probably a result of stronger aging. Over the Southern Oceans, the oxidation of DMS leads to relatively high sulfuric acid concentration. Sulfur chemistry and aerosol microphysics (nucleation, condensation and coagulation) thus become the main source of the small soluble particles. ECHAM5-HAM features stronger DMS emission (see the previous section and the last block of Table 5); additionally, in the sulfur chemistry scheme, the MSA produced from DMS is assumed to occur as sulfuric acid. In the two models using LIAM the conversion from MSA to sulfuric acid is simply ignored. Sensitivity test shows that if the same is done in ECHAM5-HAM, the near surface concentration of the soluble Aitken particles will be evidently reduced over the circumpolar trough and Antarctica (Fig. 4).

\section{CRU_obsc.png}

\subsection{Soluble accumulation mode and soluble coarse mode}

In contrast to the two modes discussed above, the soluble accumulation mode has highest concentrations near surface layers, mainly because of the primary emissions in the densely populated industrial regions and the tropical forests. These features are reasonably well captured by the three models (Figs. 1 and 3, third row). All three models also show an increase in the number concentration with altitude from around $300 \mathrm{hPa}$ (Fig. 1, third row). However, the meridional distribution and the magnitude of the concentrations in the upper troposphere differ significantly. Possible reason for that could be due to the vertical transport and wet scavenging in convective clouds, since it is known that the cumulus convection activities in the three AGCMs are considerably different (see also the following sections). The convection parameterization and its interaction with the large scale circulation is very complex. It is not yet clear how their impact can be efficiently evaluated through sensitivity experiments in this study. Further investigations are needed in the future.

The soluble coarse mode particles are introduced into the atmosphere mainly through sea salt emission and the aging of dust. The former leads to high number concentrations over the oceans, especially in the storm tracks because of strong wind, while dust emission produces high concentrations over Sahara, and over west Asia in ECHAM5-HAM (Fig. 3, last row). Note that emissions of sea salt and dust are not prescribed but calculated online in both aerosol modules used in 

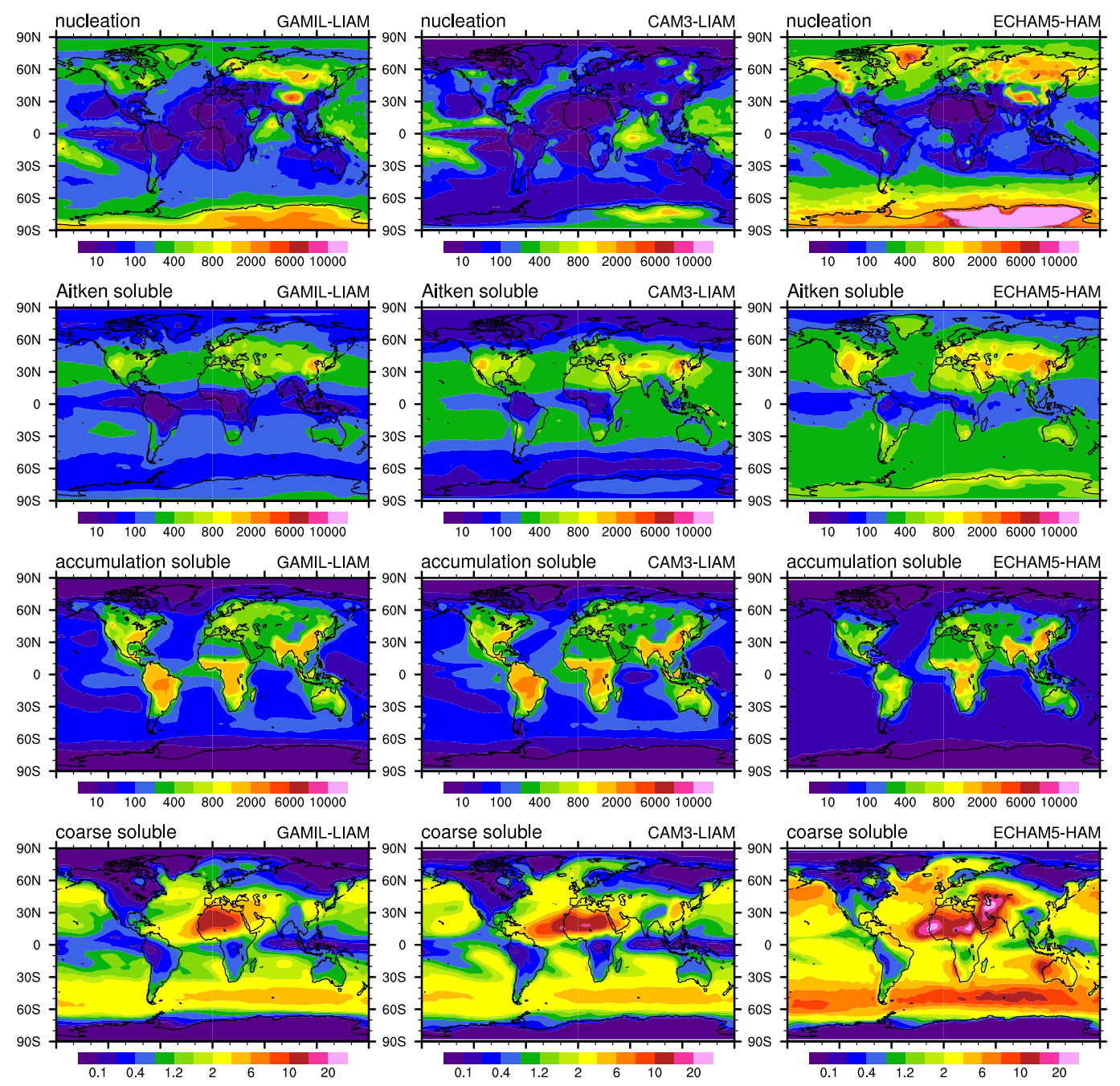

Fig. 3. Annual mean aerosol number concentration of the four soluble modes (from top to bottom) at the lowest model level simulated by GAMIL-LIAM (left column), CAM3-LIAM (middle column) and ECHAM5-HAM (right column). The unit is number of particles per cubic centimeter at the standard atmospheric state $(1013.25 \mathrm{hPa}, 273.15 \mathrm{~K})$.

this study. The parameterizations schemes used in LIAM and HAM are different, which explains the similarity between the GAMIL-LIAM simulation and the CAM3-LIAM results, as well as the large differences between these two models and ECHAM5-HAM.

In the last two rows of Fig. 3, ECHAM5-HAM produces evidently lower concentrations over the ocean in the soluble accumulation mode, and considerably higher concentrations in the coarse mode, especially over the storm tracks and in the ITCZ. This is a direct result of dramatically different sea salt emissions in ECHAM5-HAM and the two -LIAM models (Fig. 5a-c and 5e-g). The opposite discrepancies in the two modes can not be explained by $10 \mathrm{~m}$ wind speed. The next possible explanation, then, is the emission parameterization itself. To check this aspect, a sensitivity experiment is carried out using ECHAM5-HAM, but with the sea salt emission parameterization replaced by the scheme in LIAM. As expected, the sea salt emission of both modes (Fig. 5d

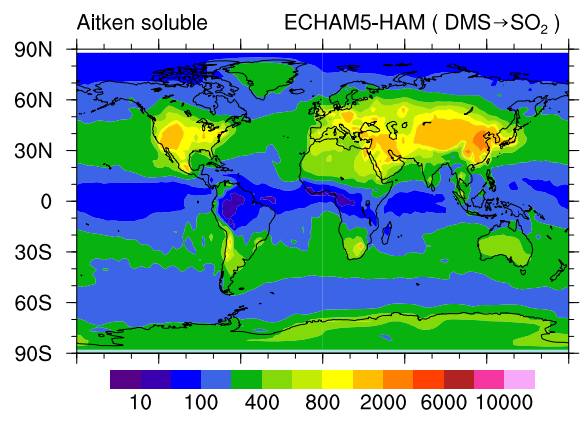

Fig. 4. Annual mean number concentration of the soluble Aitken mode particles at the lowest model level, simulated by ECHAM5HAM in the experiment in which the methane sulfonic acid (MSA) converted from dimethyl sulfide (DMS) is not assumed to occur as sulfuric acid. . The unit is number of particles per cubic centimeter at the standard atmospheric state $(1013.25 \mathrm{hPa}, 273.15 \mathrm{~K})$.

and $5 \mathrm{~h}$ ) become very similar to GAMIL/CAM3-LIAM. Note that in these simulations the aerosols have no feedback to 
the host GCM. In the sensitivity simulation the LIAM emission scheme receives exactly the same input (10 m wind) as the original scheme in ECHAM5-HAM does. Thus we can confidently conclude that the dramatic differences between the original ECHAM5-HAM and the GAMIL/CAM-LIAM in sea salt emission should be attributed to the different formulation of the parameterization schemes.

The surface concentrations of soluble accumulation mode and coarse mode in GAMIL and CAM3 differ marginally over the storm tracks due to two compensating factors: on the one hand, the circumpolar trough in the Southern Hemisphere and the low pressure systems over the North Atlantic and North Pacific are stronger in CAM3 (not shown), leading to stronger westerly wind and consequently stronger emission flux (Fig. 5a, b and 5e, f). On the other hand, the upward mass flux associated with cumulus convection is also much stronger in CAM3 in the mid-latitudes (not shown). The near surface air is therefore efficiently diluted, and more particles are transported to upper levels (Fig. 1, fourth row).

\subsection{The insoluble modes}

The insoluble particles only have emission sources. The highest concentrations thus appear near the Earth's surface (Fig. 6). Dry and wet depositions are important sinks of the insoluble particles. Additionally, the aging processes lead to loss of the insoluble aerosols by converting them to soluble particles.

For the insoluble Aitken mode aerosols, all three models utilize the same prescribed emissions for POM and BC. Understandably, the simulated near surface concentrations are quite similar, especially over the emission regions (Fig. 7, first row). The higher concentrations in the two -LIAM models over the tropical Atlantic, tropical East Pacific and the storm tracks seem related to the horizontal transport. The insoluble accumulation and coarse mode particles are released into the atmosphere only via dust emission, which is calculated online according to the characteristics of the underlying surface and the meteorological conditions (e.g., near-surface wind and atmospheric stability). The emitted dust mass is partitioned to the accumulation mode and coarse mode with a fixed ratio independent of the geographic location. Hence the concentrations of these two modes are quite similar in each individual model (Fig. 7, second and third rows). The discrepancies among the simulations over Asia and Australia are related to the different dust emission parameterizations in LIAM and HAM. In the middle and upper troposphere, the three simulations mainly differ in the tropical regions, where the number concentrations are the highest in CAM3-LIAM and lowest in ECHAM5-HAM (Fig. 6). A possible reason is the differences in the vertical transport caused by cumulus convection.

\section{Comparison with the observed particle number profiles}

In this section we compare the simulated vertical distribution of the aerosol number concentration with observations, so as to examine whether the simulations are realistic.

Annual mean tropospheric aerosol number concentration over the Pacific Ocean has been compiled by Clarke and Kapustin (2002) from several measurement campaigns ${ }^{4}$. Vertical profiles are available from the Earth's surface to $12 \mathrm{~km}$ altitude for three latitude bands: $20^{\circ} \mathrm{S}-70^{\circ} \mathrm{S}, 20^{\circ} \mathrm{S}-20^{\circ} \mathrm{N}$, and $20^{\circ} \mathrm{N}-70^{\circ} \mathrm{N}$. The regions covered by this dataset are indicated by blue boxes in Fig. 8. In the middle and upper troposphere the dataset mainly reflects the number concentration of the nucleation mode, because the size range of the measured aerosol particles was $0.003-20 \mu \mathrm{m}$, and nucleation mode number dominate total aerosol number at these higher altitudes. To carry out model evaluation, the simulated annual mean number concentration in the size range $D_{p}>0.003 \mu \mathrm{m}$ is averaged over the ocean grid point within the three blue boxes in Fig. 8 .

Figure 9 shows the observed and simulated results. Over the tropical Pacific (Fig. 9, left panel), the three models correctly capture the increase of number concentration from the near-surface layer to $11 \mathrm{~km}$. In this region the ECHAM5HAM results agree clearly better with the observation, while in GAMIL-LIAM and CAM3-LIAM the concentrations are overestimated above $5 \mathrm{~km}$. These inter-model discrepancies are consistent with the top panels in Fig. 1. In Sect. 4 we have shown that less nucleation mode aerosols are converted to larger particles in the upper troposphere in the two models using LIAM because of the relatively low concentration of sulfuric acid gas.

Over the extratropical Pacific regions (Fig. 9 middle and right panels), ECHAM5-HAM overestimates the number concentration throughout the troposphere and gives the highest value among the three models. The other two models also overestimate the number concentration above $1 \mathrm{~km}$ in the Northern Hemisphere and above $5 \mathrm{~km}$ in the Southern Hemisphere. Similar biases have been observed by Kazil et al. (2010) in an updated version of ECHAM5-HAM and by Spracklen et al. (2005) in another model.

While observations in Clarke and Kapustin (2002) provided information about clean regions and particle size corresponding to the nucleation mode, Minikin et al. (2003) presented vertical profiles over Europe in July and August 2000 for the Aitken mode $(0.014-0.1 \mu \mathrm{m})$ and accumulation mode $(0.1-3 \mu \mathrm{m})$. In this polluted region, both modes are characterized by highest concentrations near the surface caused by

\footnotetext{
${ }^{4}$ Including the Global Backscattering Expriment (GLOBE2, May 1990), the Southern Hemisphere Marine Aerosol Characterization Experiment (ACE-I, November 1995), and the Pacific Exploratory Missions PEM-Tropics A (September 1996) and PEMTropics B (March 1999).
} 

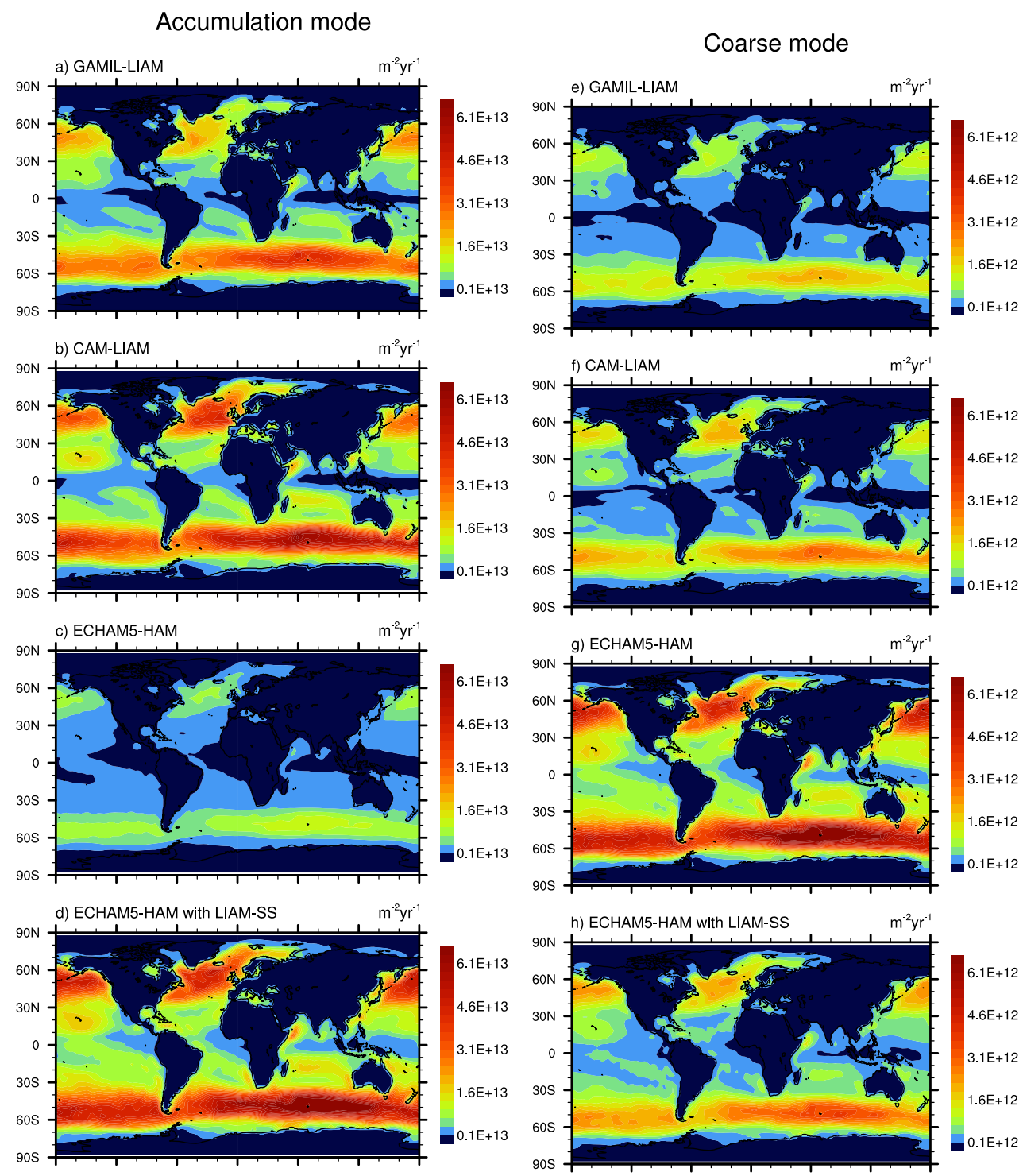

Fig. 5. Annual mean number flux of the soluble accumulation mode (left column) and soluble coarse mode (right column) caused by sea salt emission in different models and experiments. The unit is $\mathrm{m}^{-2} \mathrm{yr}^{-1}$. "LIAM-SS" refers to the sea salt emission scheme of the LIAM module.

emission, a decrease with height below $4 \mathrm{~km}$, and the almost constant concentrations between $5-10 \mathrm{~km}$ above the surface (see the black curves in Fig. 10).

The model results are averaged over the corresponding months in the region $5.3-28.8^{\circ} \mathrm{E}, 43.5-56.7^{\circ} \mathrm{N}$ (see red box in Fig. 8) to match the observation. The simulated Aitken mode profiles are similar among the three models (Fig. 10, left). The rapid decrease of concentration below $1 \mathrm{~km}$ and the weak vertical gradient between $5-10 \mathrm{~km}$ are correctly reproduced, although the concentration is evidently underestimated near surface levels and overestimated in the middle and upper troposphere. In the boundary layer, emissions and microphysics are both importance sources of the Aitken mode aerosols. The emissions used in this study are of the same year as the measurements in Minikin et al. (2003) and therefore are relatively accurate, although uncertainty exists in the particle size of the primary emission. On the other hand, in the original M7 module the ternary nucleation is not included, nor is the boundary aerosol nucleation due to cluster activation (Kulmala et al., 2006). This may have led to significant low bias in the conversion rate from nucleation mode particles to Aitken mode aerosols. In the middle and upper troposphere condensation and coagulation are the two major factors affecting the Aitken mode number concentration. Between $3.5 \mathrm{~km}$ and $10 \mathrm{~km}$ altitude the model results are slightly higher than observation. 

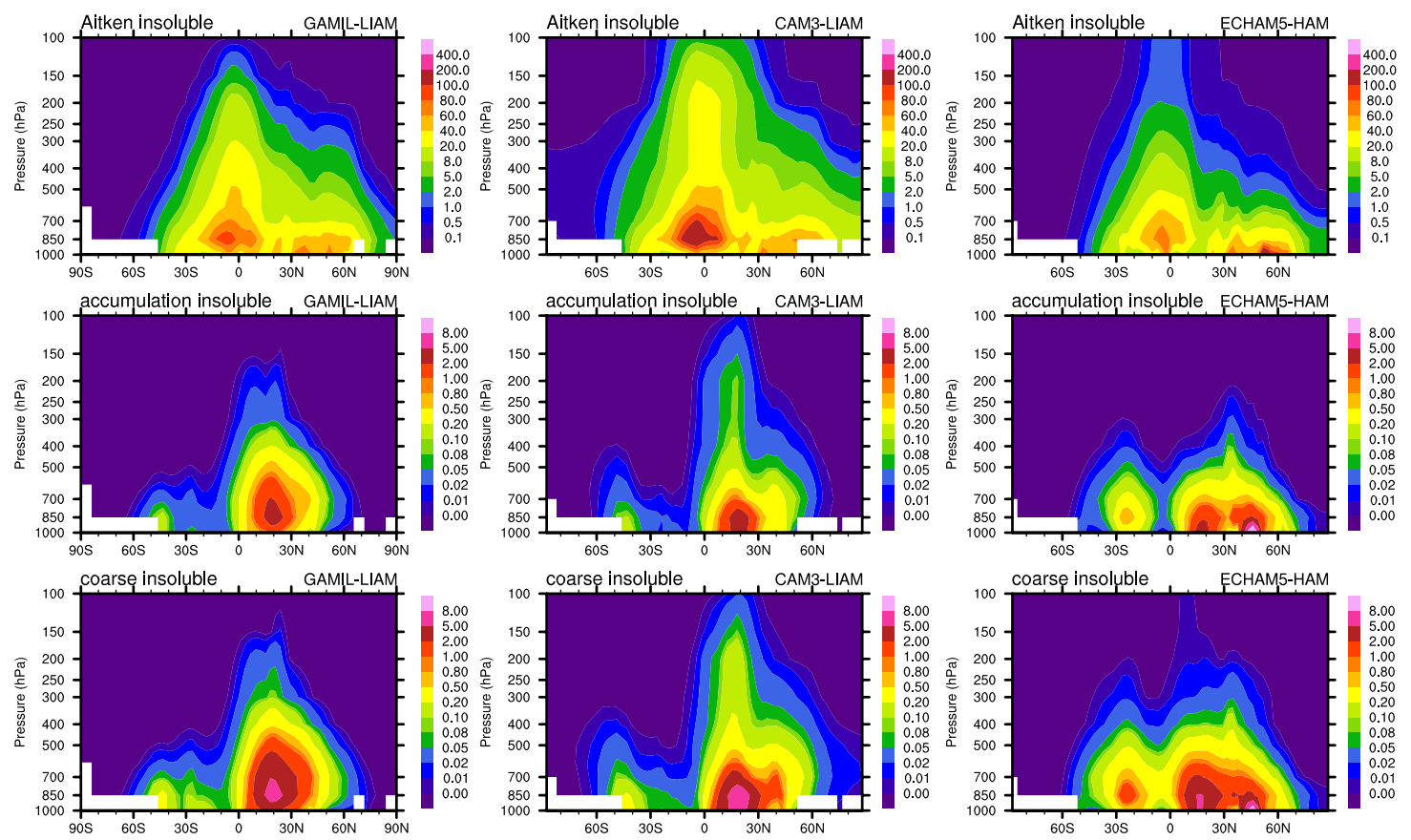

Fig. 6. Zonal and annual mean aerosol number concentration of the three insoluble modes (from top to bottom) simulated by GAMIL-LIAM (left column), CAM3-LIAM (middle column) and ECHAM5-HAM (right column). The unit is number of particles per cubic centimeter at the standard atmospheric state $(1013.25 \mathrm{hPa}, 273.15 \mathrm{~K})$.
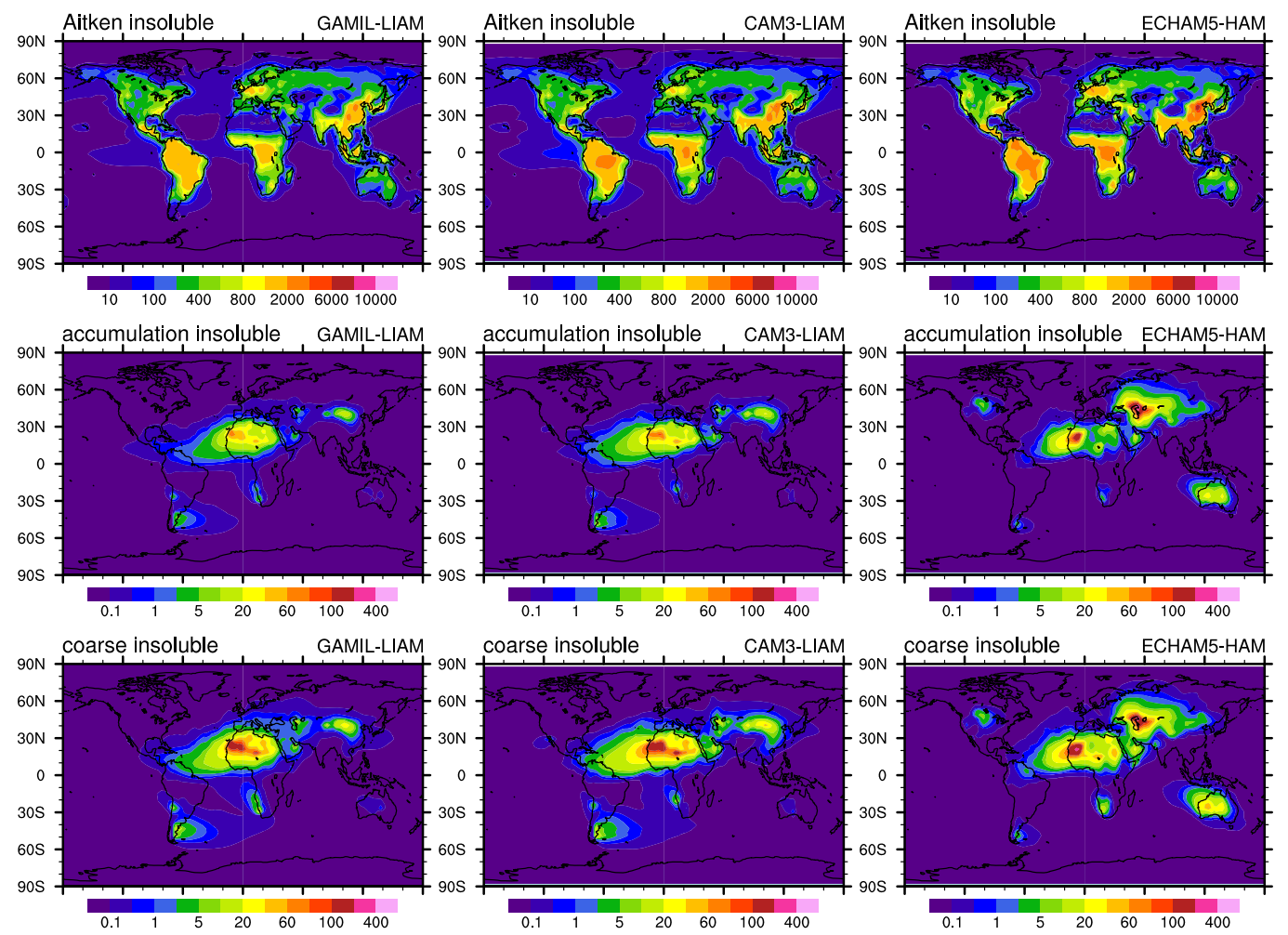

Fig. 7. Annual mean aerosol number concentration of the three insoluble modes (from top to bottom) at the lowest model level simulated by GAMIL-LIAM (left column), CAM3-LIAM (middle column) and ECHAM5-HAM (right column). The unit is number of particles per cubic centimeter at the standard atmospheric state $(1013.25 \mathrm{hPa}, 273.15 \mathrm{~K})$. 


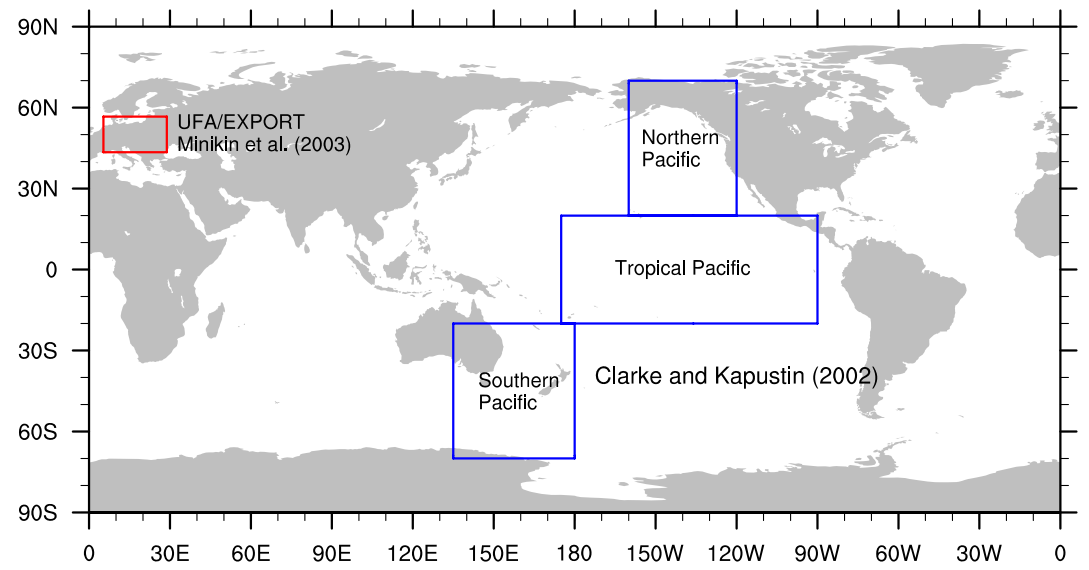

Fig. 8. The Pacific (blue) and European (red) regions in which the simulated aerosol number concentration profiles are compared against observations. See Sect. 5 for further information.
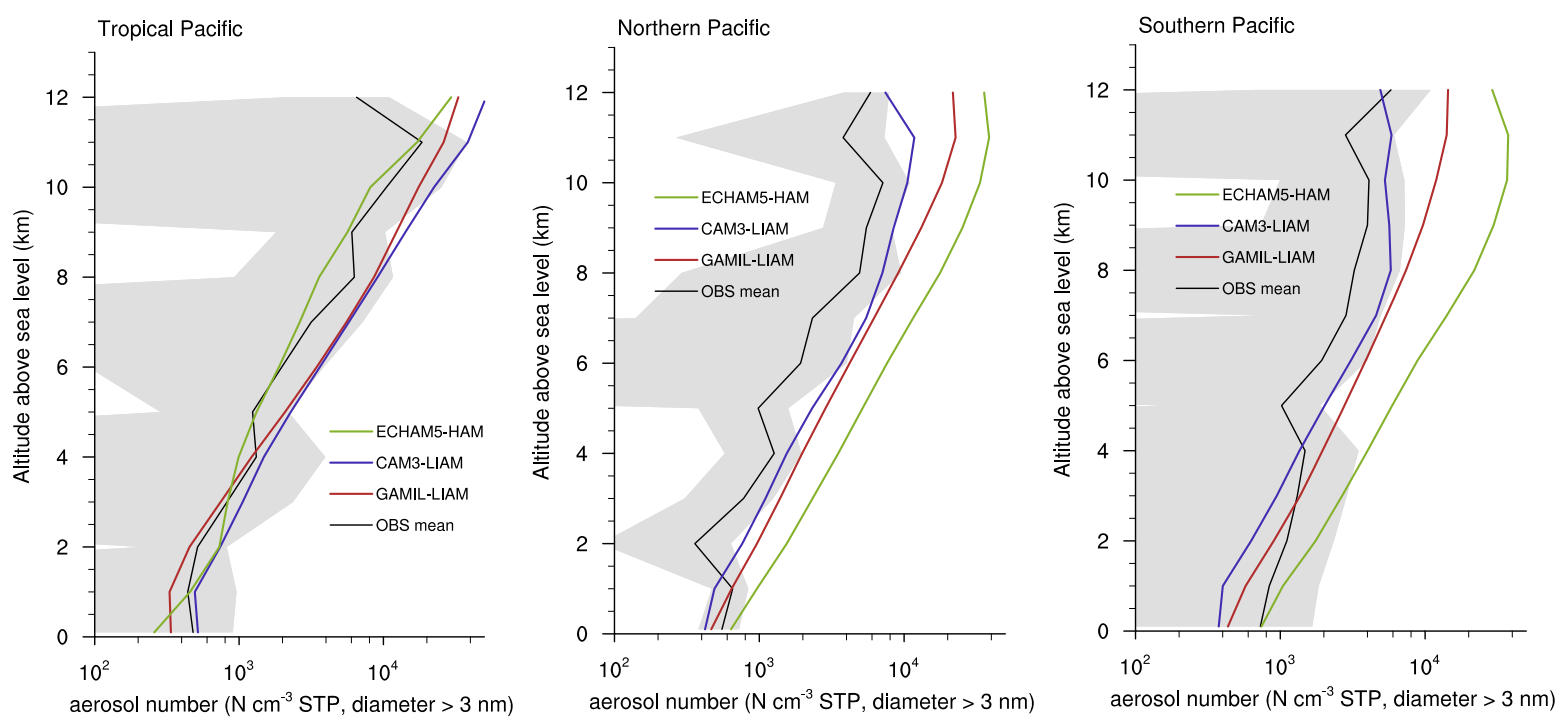

Fig. 9. Comparison between the simulated and observed particle number concentrations over the tropical (left), northern (middle) and southern (right) Pacific regions. The simulated profiles are derived from the total $\left(D_{p}>3 \mathrm{~nm}\right)$ aerosol number concentrations averaged over the ocean grid points in the blue boxes shown in Fig. 8. The observations were compiled by Clarke and Kapustin (2002) from measurements obtained in the 1990's (see Fig. 9 therein). The grey shading indicates the standard deviation of the observed profiles.

As for the accumulation mode (Fig. 10, right), the three models are able to capture the trend of decreasing concentration with altitude. From the surface to $7 \mathrm{~km}$, the simulated values are generally within the 10- and 90-percentiles of the observations. On the other hand, evident differences exist among models and between simulation and measurement. Features of the discrepancies are consistent with the zonal mean cross sections discussed in the previous section (see the third row of Fig. 1).

\section{Comparison with the observed size distributions in the boundary layer}

In this section we compare aerosol size distributions in the three models with several sets of observational data in the boundary layer. Size distribution measurements available in the literature are sparse in terms of spatial and temporal coverage. The techniques for measurement and data analysis are often not standard. The simulations in this study are performed using global models of relatively coarse resolution, driven by climatological SST/sea ice data and the emissions scenario of the year 2000. These factors make it not straightforward to quantitatively evaluate the model results. 

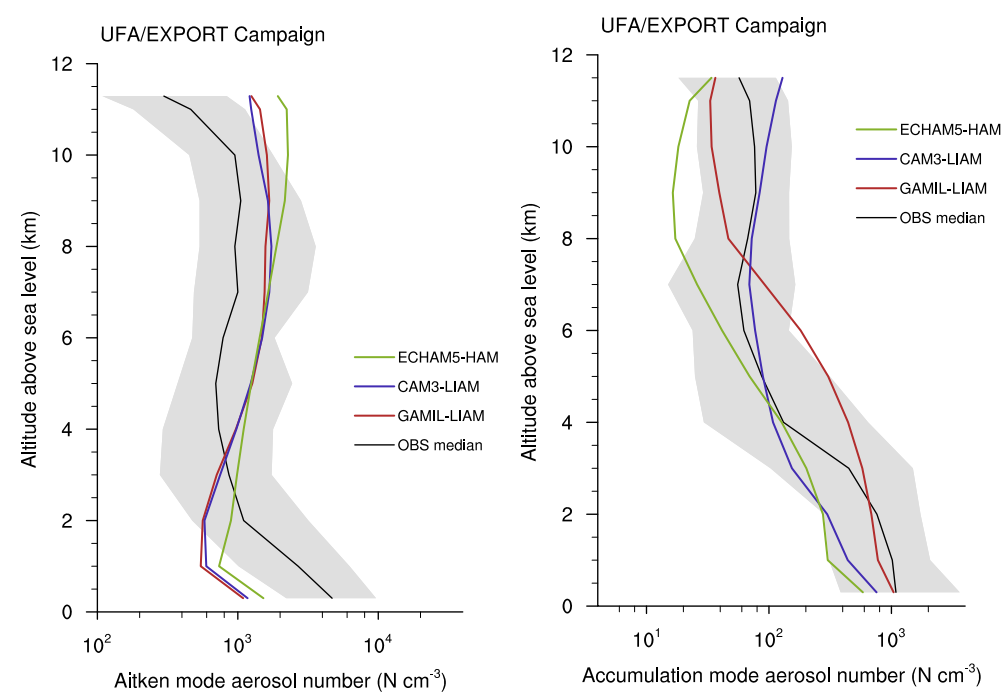

Fig. 10. Comparison between the simulated and observed Aitken (left) and accumulation (right) mode number concentrations over Europe. The simulated profiles are July and August averages in the red box shown in Fig. 8. The observations were compiled by Minikin et al. (2003) using the measurements obtained in July and August 2000 during the UFA/EXPORT campaign. The boundaries of the shaded areas indicate the 10th and 90th percentiles of the observational data.

Nevertheless we still make such comparisons in this section while keeping in mind the large uncertainties associated. The purpose is to find out whether the models can capture the main features of the size distributions in typical situations, and to what extent the three models disagree with each other.

Given that the modal method is used for representing aerosol size distribution in our models, the most useful observations in the literature are those compiled into multi-modal log-normal distributions by the original investigators. These include direct measurements of aerosol distribution obtained at observatories, during cruises and in special campaigns, as well as indirect measurements provided by the AERONET. Most of the direct measurements feature dry aerosol distributions in the boundary layer, while AERONET provides the wet aerosol distributions vertically integrated over the whole extent of the atmosphere. For the first step of model evaluation we chose not to compare vertical integrals in order to avoid fake correct results caused by canceling error. Therefore in this section, we compare the simulated dry aerosol distributions with boundary layer observations, and leave the task of comparison against AERONET data for future work. In the following, we focus on examining whether the parameters of the distribution functions are reasonably reproduced by the models.

\subsection{Over the continents and coastal regions}

Putaud et al. (2003) compiled aerosol size distribution measurements from 10 European surface sites during the period 1997-2001. Three-mode distribution functions are fitted to the original data and the log-normal mode parameters are provided in their publication. For comparison with model simulations, only the observations obtained at natural and rural sites (Aspvretren, Harwell and Hohenpeissenberg) are used here. Furthermore, as the influence of local emission can be clearly detected at Harwell and Hohenpeissengberg during daytime, only the nighttime measurements are used. The black curves in Fig. 11 display the observed median size distribution. Regarding the model simulations (colored curves in Fig. 11), only the diameter range of $0.01-0.8 \mu \mathrm{m}$ of the calculated distribution functions are presented because smaller and larger particles are not measured in Putaud et al. (2003).

Figure 11 shows the observed and simulated size distributions in winter (top row) and summer (bottom row) at the aforementioned sites. The aerosol size spectra at polluted sites are characterized by overlapping Aitken and accumulation modes. This is correctly reproduced by all three models. On the whole, the magnitude of the simulated distribution functions agree reasonably with the observation, although discrepancies exist in details of the spectra. For example, at Harwell, underestimate of the number concentration is evident in the accumulation mode in winter and over a broad range from 0.03 to $0.4 \mu \mathrm{m}$ in summer. The seasonal changes are much less evident in the models than in reality. At the coastal site Aspvretren, all three models underestimate the number concentration in winter, and overestimate the two tails of the spectrum in summer. Systematic inter-model discrepancy, on the other hand, is not evident. 

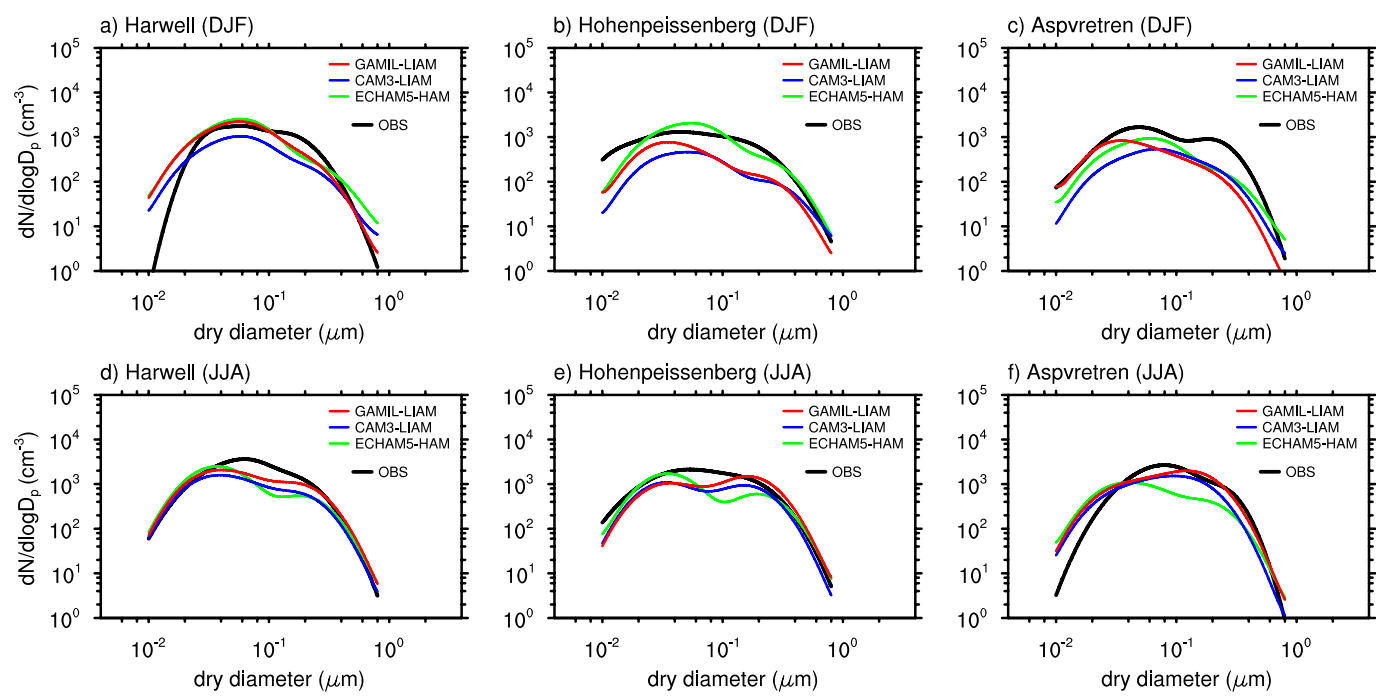

Fig. 11. Comparison between the simulated and observed aerosol size distributions in the continental and coastal boundary layer over Europe. The observations were compiled by Putaud et al. (2003) (see Appendix 3 therein).

\subsection{Over the remote oceans}

Aerosol size distributions in the marine boundary layer (MBL) have been compiled by Heintzenberg et al. (2000) from some 30 years of cruise and flight measurements for the brown boxes shown in Fig. 12. Each box indicates a $15^{\circ} \times 15^{\circ}$ (latitude $\times$ longitude) area. The number concentration, geometric mean diameter and standard deviation of the log-normal distribution function were derived for the Aitken and accumulation modes for 10 latitude bands (see Table 3 therein). These data are visualized by solid black curves in Fig. 12a-j. The $\sigma_{1}$ and $\sigma_{2}$ values in each panel are the standard deviations of the Aitken mode and accumulation mode, respectively. It is worth noting that while the prescribed standard deviations of both modes are 1.59 in the M7 module, the observed values are often smaller.

The simulated size distributions in the brown boxes are averaged in each latitude band and presented by colored curves in Fig. 12. Most of the sampling regions are over the remote oceans, for which it is now well known that the size distribution is characterized by a clear separation between welldefined Aitken mode and accumulation mode. This feature is correctly captured by all three models.

Aitken mode aerosols in the remote MBL originate mainly from particle formation and growth due to sulfur chemistry and microphysics, and horizontal transport which increases the concentrations over the downwind oceans. The simulations generally agree well with observations. In the polar regions (especially between $45^{\circ} \mathrm{S}$ and $75^{\circ} \mathrm{S}$ ) the Aitken mode concentrations in the two -LIAM models are evidently lower than in ECHAM5-HAM. This has been noticed when discussing Fig. 3 in Sect. 4.1. There it was pointed out that whether or not to consider the conversion of MSA to sulfuric acid makes a difference. Here in Fig. 12i, $\mathrm{j}$ the ECHAM5HAM results agree better with the observation data, suggesting that the treatment of MSA in HAM is more appropriate.

Accumulation mode particles in the marine boundary layer mainly come from sea salt emission. In Sect. 4.2 we found that the sea salt emission scheme in HAM produces significantly weaker emission flux in this mode and consequently much lower number concentration. This can be clearly seen in Fig. 12 as well. The systematic discrepancy disappears when the LIAM sea salt emission scheme is used in ECHAM5-HAM (see dashed curves in Fig. 12). Another point worth noting is that all three models have underestimated the concentration of the accumulation mode. The cause is not yet clear. The simulated $10 \mathrm{~m}$ wind speeds (which strongly affect sea salt emission) have been compared against the ERA-Interim reanalysis (now shown), but can not explain the bias.

\subsection{Over the China adjacent seas}

Lin et al. (2007) reported aerosol size distributions and particle number concentrations in the diameter range from $15 \mathrm{~nm}$ to $10 \mu \mathrm{m}$, measured during three cruises over the China adjacent seas (Fig. 13f). Two of the cruises were in the Yellow Sea in March 2005 and April 2006, while the other covered the Yellow Sea, the East China Sea and the South China Sea in May 2005. The observed number size distributions have been fitted to three log-normal modes (Aitken, accumulation, and coarse modes) in Lin et al. (2007). To compare with these data, the simulated aerosol size distributions in the grid boxes reached by each cruise are averaged for the corresponding month. 

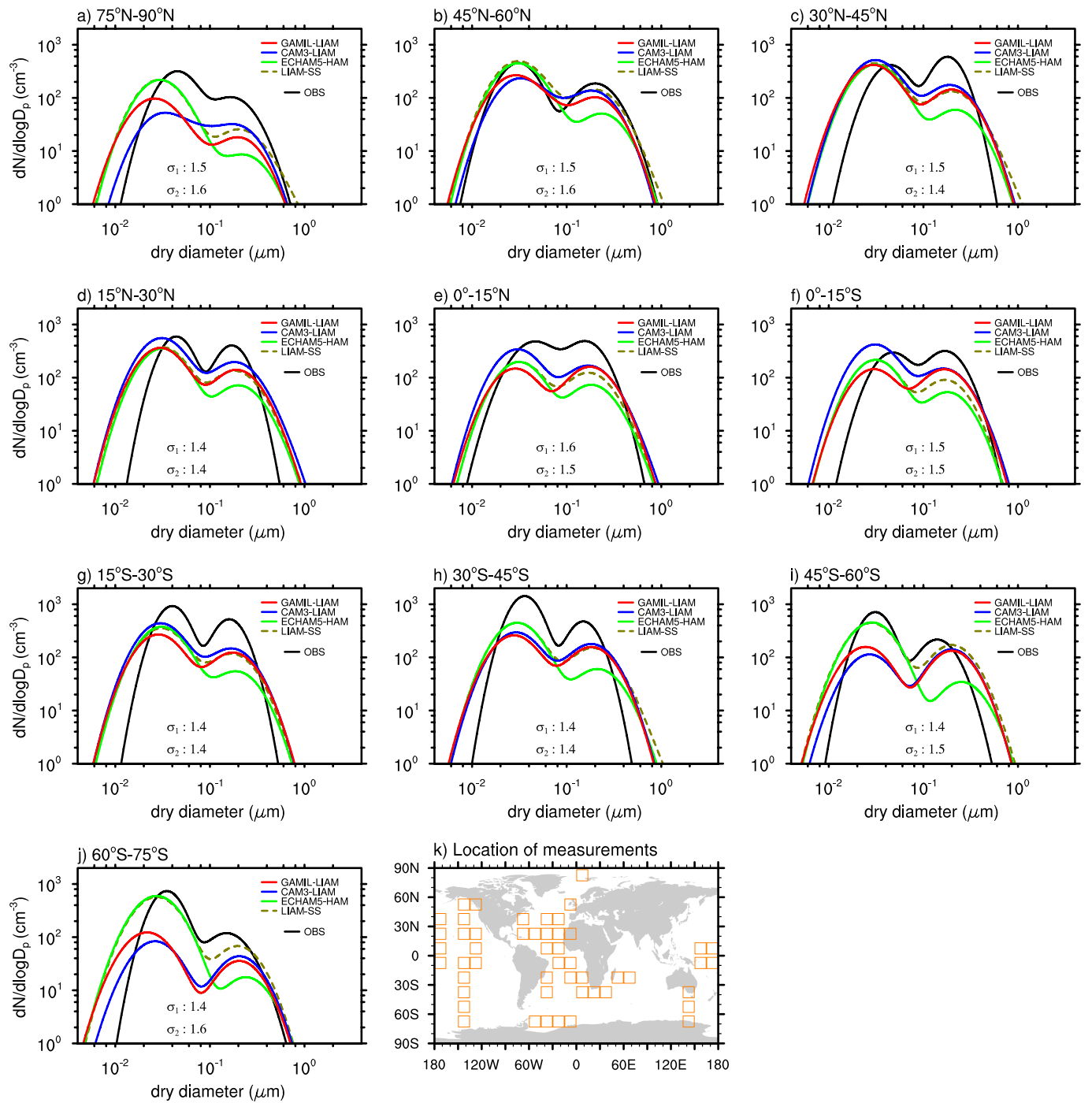

Fig. 12. Comparison between the simulated and observed aerosol size distributions of the Aitken and accumulation modes in the marine boundary layer. The simulated distributions include both the soluble and the insoluble modes. The observations were compiled by Heintzenberg et al. (2000) (see Table 3 therein).

The most important feature in Fig. 13 is that over the Yellow Sea and East China Sea the three models give very similar results, and they all lie well within the observed 5thand 95th-percentile, while significant negative biases in number concentration are seen over the South China Sea. Climate data reveal that the Yellow Sea and East China Sea are most often affected by polluted air coming from the continent to their west. The South China Sea, in contrast, is a tricky region in which the near surface wind can change direction dramatically at synoptic time scale. During the observation period in Lin et al. (2007) the weather condition was relatively stable. Back-trajectory study showed that the air masses came from the heavily polluted Luzon Island and Visayan Island in the east (Lin et al., 2007). The severe un- derestimate of the number concentration by all three models (Fig. 13e), especially in the accumulation mode, is probably related to the differences in the modeled and observed circulation.

\section{$7 \quad$ Summary and conclusions}

In this study the tropospheric aerosol size distributions simulated by three global models are compared and evaluated against observations. All three models are general circulation models in which the aerosol-related physical and chemical processes are calculated online. Two of the models, GAMIL-LIAM and CAM3-LIAM, use the same aerosol module LIAM and differ only in model meteorology; the 

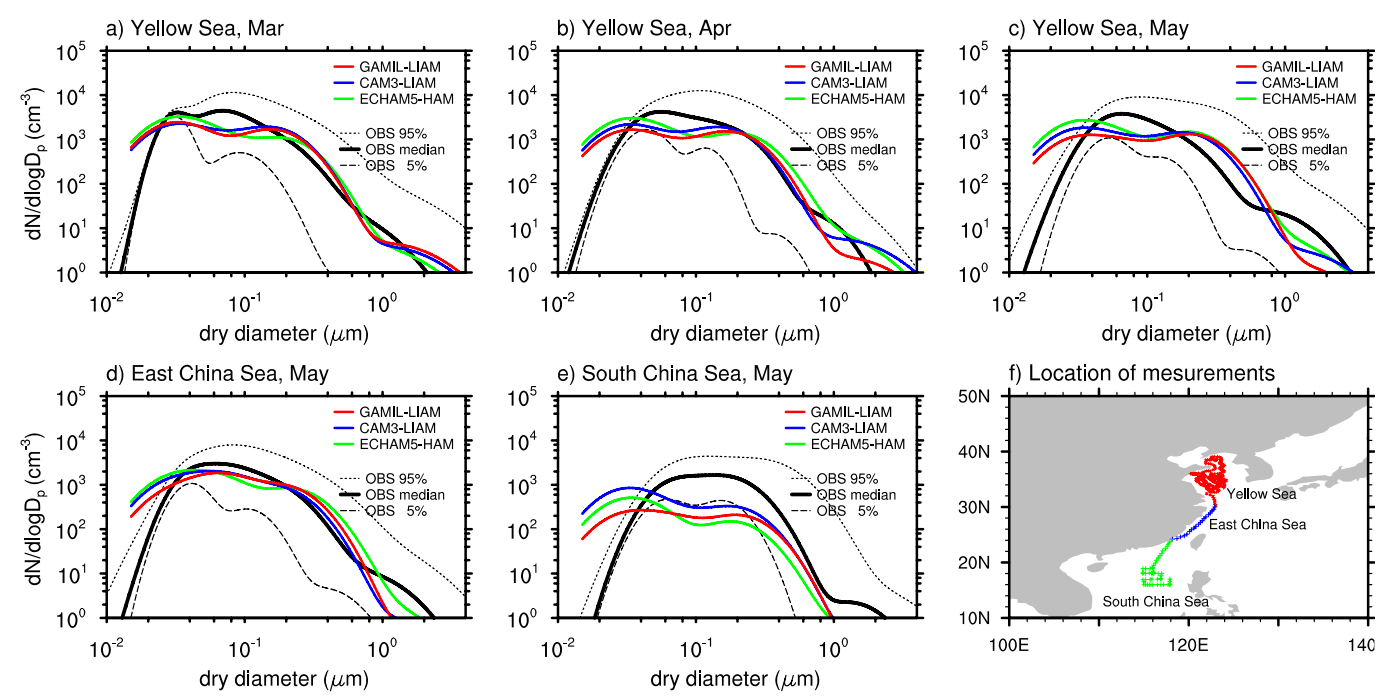

Fig. 13. Comparison between the simulated and observed aerosol size distributions in the marine boundary layer over China adjcent seas. The simulated distributions are the sum of all the modes resolved by the M7 module. The observations were compiled by Lin et al. (2007) (see Table 2 therein).

aerosol module HAM coupled to the ECHAM5 model differs from LIAM in the sulfur chemistry scheme, the treatment of natural aerosol emissions as well as the deposition processes.

The unique feature of the simulations performed here is that the same modal method is used for representing the size distribution of the aerosol population. The analysis of the model results is carried out from two aspects: the aerosol number concentration of each resolved mode, and the characteristics of the simulated aerosol size distributions (mode radius and standard deviation). The number concentrations of all the modes resolved in the M7 microphysics module are compared separately among the three models. The annual and zonal mean concentrations in the troposphere and the annual mean surface concentrations are examined. On the whole the qualitative features of the spatial distributions are similar in the three simulations. In the zonal mean cross section, high concentrations of the nucleation mode appear near the tropopause, while the soluble coarse mode particles and the insoluble aerosols are concentrated in the near-surface layers. The characteristic magnitude of the number concentration of each mode is also consistent among the three models.

Quantitative differences are also clearly detectable:

for the soluble and insoluble coarse and accumulation modes, inter-model discrepancies mainly result from the differences in the SS and DU emissions and the convective transport. The SS emission parameterization in LIAM produces much weaker aerosol number flux in the coarse mode than the scheme in HAM, and stronger flux in the accumulation mode; the different DU emission schemes lead to considerable discrepancies in the horizontal pattern of the number concentration in these two modes; the impact of the different strengths of convective transport can be most clearly detected in the vertical distribution of the concentrations, especially in the tropics and in the middle and upper troposphere.

Regarding the number concentrations of the nucleation mode and soluble Aitken mode, the spread of the model results is larger in the equatorial regions in the upper troposphere. The differences between the LIAM simulations and the ECHAM5-HAM result are evidently larger than between GAMIL-LIAM and CAM3-LIAM. Diagnostics indicate that the sulfur cycle is considerably more active in ECHAMHAM. Compared to other studies in the literature, the condensation rate of sulfuric acid gas in ECHAM5-HAM appears to be the highest, while the corresponding values in the two -LIAM models are among the lowest. Sensitivity experiments suggest that the dramatic differences are probably caused by the different parameterizations of sulfur chemistry or the related meteorological conditions.

The annual and zonal mean number concentration of the soluble accumulation mode in the upper troposphere is surprisingly different among the three models. The cause is not yet clear and further investigations are needed.

In addition to model intercomparison, the simulations are also evaluated against observations. Over Europe and the Pacific Ocean, the simulated and observed vertical distributions of the aerosol number concentrations are compared. All three models can reasonably reproduce the increase of aerosol number concentrations with altitude over clean areas (the Pacific Ocean), and the decrease of Aitken and accumulation mode number concentrations in the polluted regions (Europe). There are also evident differences in the detailed features of the profiles, both between measurements and simulations, and between results from different models. It is worth 
noting that the model results are obtained under climatological SST forcing and the emission scenario of year 2000, and the simulated profiles are derived from monthly mean output. In contrast, the observational data were compiled from flight measurements strongly affected by the weather conditions. To reduce the uncertainties in the quantitative comparison between observations and simulations, it is necessary to either compile more measurements covering longer time periods, or perform nudged model simulations and derive the diagnostics using instantaneous model output at higher frequencies.

Aerosol size distributions simulated by all three models are compared with observations in the boundary layer. The overall results are encouraging. In the polluted regions over the continents, the high number concentrations over the broad range from $0.002 \mu \mathrm{m}$ to $0.4 \mu \mathrm{m}$ can be correctly captured. Over the remote oceans, the relatively low concentrations and the separation of Aitken and accumulation modes are also reasonably reproduced. Over the Yellow Sea and the East China Sea where the large-scale circulation is dominated by westerly winds from the continent, the simulated size spectra are very similar among the three models, and also close to the observation. Over the South China Sea where the near surface winds feature much stronger variability, simulation and observation can differ considerably.

For the next steps, we plan to investigate why the sulfur cycle simulated by ECHAM5-HAM is so different from the other two models. In addition, the size distribution derived from the AERONET optical depth and Angstrom measurements will be used to evaluate the simulated wet aerosol size distribution.

Acknowledgements. The authors are grateful to S. Kinne, P. Stier, Y. Peng, and B. Stevens for their suggestions and constructive criticisms. We also would like to thank both of the two anonymous reviewers for their helpful comments. We acknowledge the Fund for Innovative Research Groups Grant 40821092 and the financial support from the 973 Project Grant 2005CB321703. XL was funded by the US Department of Energy, Office of Science, Scientific Discovery through Advanced Computing (SciDAC) program. The Pacific Northwest National Laboratory is operated for the DOE by Battelle Memorial Institute under contract DE-AC06-76RLO 1830. KZ was partially supported by the exchange program of the IMPRS-ESM and the PhD Student Promotion Project of the Max Planck Society and the Chinese Academy of Sciences.

The service charges for this open access publication have been covered by the Max Planck Society.

Edited by: K. Lehtinen

\section{References}

Barth, M., Rasch, P. J., Kiehl, J. T., Benkovitz, C. M., and Schwartz, S. E.: Sulfur chemistry in the NCAR CCM: Description, evaluation, features and sensitivity to aqueous chemistry, J. Geophys. Res., 105, 1387-1415, 2000.

Bauer, S. E., Wright, D. L., Koch, D., Lewis, E. R., McGraw, R., Chang, L.-S., Schwartz, S. E., and Ruedy, R.: MATRIX (Multiconfiguration Aerosol TRacker of mIXing state): an aerosol microphysical module for global atmospheric models, Atmos. Chem. Phys., 8, 6003-6035, doi:10.5194/acp-8-60032008, 2008.

Briegleb, B. P.: Delta-Eddington approximation for solar radiation in the NCAR Community Climate Model, J. Geophys. Res., 97, 7603-7612, 1992.

Brinkop, S. and Roeckner, E.: Sensitivity of a general circulation model to parameterizations of cloud-turbulence interactions in the atmospheric boundary layer, Tellus, 47A, 197-220., 1995.

Clarke, A. D. and Kapustin, V. N.: A Pacific Aerosol Survey. Part I: A Decade of Data on Particle Production, Transport, Evolution, and Mixing in the Troposphere, J. Atmos. Sci., 59, 363382, 2002.

Collins, W. D. P. J. R., Boville, B. A., Hack, J. J., McCaa, J. R., Williamson, D. L., Kiehl, J. T., Briegleb, B., Bitz, C., Lin, S.-J., Zhang, M., and Dai., Y.: Description ofthe NCAR Community Atmosphere Model (CAM 3.0)., NCAR Technical Note NCAR/TN-464+STR, National Center for Atmospheric Research, online available at: http://www.ccsm.ucar.edu/models/ atm-cam/docs/description/, 2004.

Dentener, F., Kinne, S., Bond, T., Boucher, O., Cofala, J., Generoso, S., Ginoux, P., Gong, S., Hoelzemann, J. J., Ito, A., Marelli, L., Penner, J. E., Putaud, J.-P., Textor, C., Schulz, M., van der Werf, G. R., and Wilson, J.: Emissions of primary aerosol and precursor gases in the years 2000 and 1750 prescribed data-sets for AeroCom, Atmos. Chem. Phys., 6, 4321-4344, doi:10.5194/acp6-4321-2006, 2006.

Easter, R. C., Ghan, S. J., Zhang, Y., Saylor, R. D., Chapman, E. G., Laulainen, N. S., Abdul-Razzak, H., Leung, L. R., Bian, X., and Zaveri, R. A.: MIRAGE: Model description and evaluation of aerosols and trace gases, J. Geophys. Res., 109, D20210, doi:10.1029/2004JD004571, 2004.

Feichter, J., Kjellström, E., Rodhe, H., Dentener, F., Lelieveld, J., and Roelofs, G. J.: Simulation of the tropospheric sulfur cycle in a global climate model, Atmos. Environ., 30, 1693-1707, 1996.

Fouquart, Y. and Bonnel, B.: Computations of solar heating of the earths atmosphere: A new parameterization, Beitr. Phys. Atmos., 53, 35-62, 1980.

Ganzeveld, L. and Lelieveld, J.: Dry Deposition parameterization in a chemical general circulation model and its influence on the distribution of reactive trace gases, J. Geophys. Res., 100, 2099921012, 1995.

Ganzeveld, L., Lelieveld, J., and Roelofs, G.-J.: A dry deposition parameterization for sulfur oxides in a chemistry and general circulation model, Atmos. Environ., 103, 5679-5694., doi:10.1029/97JD03077, 1998.

Ghan, S. J., Laulainen, N. S., Easter, R. C., Wagener, R., Nemesure, S., Chapman, E. G., Zhang, Y., and Leung, L. R.: Evaluation of aerosol direct radiative forcing in MIRAGE, J. Geophys. Res., 106, 5295-5316, 2001.

Gong, S. L.: A parameterization of sea-salt aerosol source function 
for sub- and super-micron particles, Global Biogeochem. Cy., 17, 1097, doi:10.1029/2003GB002079, 2003.

Gong, S. L., Barrie, L. A., and Blanchet, J. P.: Modeling sea-salt aerosols in the atmosphere 1. Model development, J. Geophys. Res., 102, 3805-3818, 1997.

Guelle, W., Schulz, M., Balkanski, Y., and Dentener, F.: Influence of the source formulation on modeling the atmospheric global distribution of sea salt aerosol, J. Geophys. Res., 106, 2750927524, 2001.

Hack, J. J.: Parameterization of moist convection in the National Center for Atmospheric Research Community Climate Model (CCM2), J. Geophys. Res., 99, 5551-5568, 1994.

Heintzenberg, J., Covert, D. C., and van Dingenen, R.: Size distribution and chemical composition of marine aerosols: a compilation and review, Tellus, 52B, 1104-1122, 2000.

Herzog, M., Weisenstein, D. K., and Penner, J. E.: A Dynamic Aerosol Module for Global Chemical Transport Models: Model Description, J. Geophys. Res., 109, D18202, doi:10.1029/2003JD004405, 2004.

Holtslag, A. A. M. and Boville, B. A.: Local versus nonlocal boundary-layer diffusion in a global climate model, J. Climate, 6, 1825-1842, 1993.

Horowitz, L. W., Walters, S., Mauzerall, D. L., Emmons, L. K., Rasch, P. J., Granier, C., Tie, X., Lamarque, J.-F., Schultz, M. G., Tyndall, G. S., Orlando, J. J., and Brasseur, G. P.: A global simulation of tropospheric ozone and related tracers: Description and evaluation of MOZART, version 2, J. Geophys. Res., 108, 4784, doi:10.1029/2002JD002853, 2003.

IPCC: Climate change 2007: the physical science basis, Cambridge University Press, 2007.

Jacobson, M. Z.: GATOR-GCMM: A global- through urban-scale air pollution and weather forecast model. 1. Model design and treatment of subgrid soil, vegetation, roads, rooftops, water, sea ice, and snow, J. Geophys. Res., 106, 5385-5402, 2001.

Kazil, J. and Lovejoy, E. R.: A semi-analytical method for calculating rates of new sulfate aerosol formation from the gas phase, Atmos. Chem. Phys., 7, 3447-3459, doi:10.5194/acp-7-3447-2007, 2007.

Kazil, J., Stier, P., Zhang, K., Quaas, J., Kinne, S., O’Donnell, D., Rast, S., Esch, M., Ferrachat, S., Lohmann, U., and Feichter, J.: Aerosol nucleation and its role for clouds and Earth's radiative forcing in the aerosol-climate model ECHAM5-HAM, Atmos. Chem. Phys. Discuss., 10, 12261-12308, doi:10.5194/acpd-1012261-2010, 2010.

Kerkweg, A., Buchholz, J., Ganzeveld, L., Pozzer, A., Tost, H., and Jöckel, P.: Technical Note: An implementation of the dry removal processes DRY DEPosition and SEDImentation in the Modular Earth Submodel System (MESSy), Atmos. Chem. Phys., 6, 4617-4632, doi:10.5194/acp-6-4617-2006, 2006.

Kulmala, M., Laaksonen, A., and Pirjola, L.: Parameterizations for sulfuric acid/water nucleation rates, J. Geophys. Res., 103, 83018307, 1998.

Kulmala, M., Lehtinen, K. E. J., and Laaksonen, A.: Cluster activation theory as an explanation of the linear dependence between formation rate of $3 \mathrm{~nm}$ particles and sulphuric acid concentration, Atmos. Chem. Phys., 6, 787-793, doi:10.5194/acp-6-787-2006, 2006.

Langner, J. and Rodhe, H.: A global three-dimensional model of tropospheric sulfur cycle, J. Atmos. Chem., 13, 225-263, 1991.
Lin, P., Hu, M., Wu, Z., Niu, Y., and Zhu, T.: Marine aerosol size distributions in the springtime over China adjacent seas, Atmos. Environ., 41, 2183-2205, 2007.

Liousse, C., Penner, J. E., Chuang., C., Walton, J. J., Eddleman, H., and Cachier, H.: A global three-dimensional model study of carbonaceous aerosols, J. Geophys. Res., 101, 19411-19432, doi:10.1029/95JD03426, 1996.

Lin, S. J. and Rood, R. B.: Multidimensional flux-form semiLagrangian transport schemes, Mon. Weather Rev., 124, 20462070, 1996.

Liu, X., Penner, J. E., and Herzog, M.: Global modeling of aerosol dynamics: Model description, evaluation, and interactions between sulfate and nonsulfate aerosols, J. Geophys. Res., 110, D18206, doi:10.1029/2004JD005674, 2005.

Liu, X., Penner, J. E., Das, B., Bergmann, D., Rodriguez, J. M., Strahan, S., Wang, M., and Feng, Y.: Uncertainties in global aerosol simulations: Assessment using three meteorological data sets, J. Geophys. Res., 112, D11212, doi:10.1029/2006JD008216, 2007.

Lohmann, U. and Roeckner, E.: Design and performance of a new cloud microphysics scheme developed for the ECHAM general circulation model, Clim. Dynam., 12, 557-572, 1996.

Lohmann, U., Stier, P., Hoose, C., Ferrachat, S., Kloster, S., Roeckner, E., and Zhang, J.: Cloud microphysics and aerosol indirect effects in the global climate model ECHAM5-HAM, Atmos. Chem. Phys., 7, 3425-3446, doi:10.5194/acp-7-3425-2007, 2007.

Louis, J. F.: A parametric model of vertical eddy uses in the atmosphere, Bound.-Lay. Meteorol., 17, 187-202, 1979.

McGraw R.: Description of atmospheric aerosol dynamics by the quadrature moment of methods, Aerosol Sci. Tech., 27, 255-265, 1997.

Minikin, A., Petzold, A., Fiebig, M., Hendricks, J., and Schroeder, F.: Aerosol Properties Measured In Situ in the Free Troposphere and Tropopause Region at Midlatitudes, in: European Aerosol Conference, Madrid, E, 31 August-5 September 2003, vol. 34, S1155-S1156, 2003.

Mlawer, E. J., Taubman, S. J., Brown, P. D., Iacono, M. J., and Clough, S. A.: Radiative transfer for inhomogeneous atmospheres: RRTM, a validated correlated-k model for the longwave, J. Geophys. Res., 102, 16663-16682, 1997.

Monahan, E., Spiel, D., and Davidson, K.: A model of marine aerosol generation via whitecaps and wave disruption, in: Oceanic whitecaps and their role in air-sea exchange, edited by: Reidel, D., 167-174, Norwell, Massachusetts, 1986.

Morcrette, J.-J., Clough, S. A., Mlawer, E. J., and Iacono, M. J.: Impact of a validated radiative transfer scheme, RRTM, on the ECMWF model climate and 10-day forecasts, ECMWF technical memorandum 252, European Centre for Medium-Range Weather Forecast, Reading, UK, 1998.

Müller, J.-F. and Brasseur, G.: IMAGES: A three-dimensional chemical transport model of the global troposphere, J. Geophys. Res., 100, 16445-16490, 1995.

Nordeng, T. E.: Extended versions of the convective parametrization scheme at ECMWF and their impact on the mean and transient activity of the model in the tropics, ECMWF Research Department, Technical Momorandum 206, European Centre for Medium-Range Weather Forecast, Reading, UK, 1994.

Putaud, J. P. and Dingenen, R. V., Baltensperger, U., et al.: A Euro- 
pean aerosol phenomenology; physical and chemical characteristics of particulate matter at kerbside, urban, rural and background sites in Europe, Tech. Rep. Report nr. EUR 20411, European Commission, online available at: http://ccu.jrc.it/Pubblications/ putaud_JF1_pdfPM-draft_02Jul.pdf, 2003.

Rasch, P. J. and Kristjansson, J. E.: A comparison of the CCM3 model climate using diagnosed and predicted condensate parameterizations, J. Climate, 11, 1587-1614, 1998.

Roeckner, E., Bäuml, G., Bonaventura, L., et al.: The atmospheric general circulation model ECHAM 5. PART I: model description, MPI Technical Report 349, Max Planck Institute for Meteorology, Hamburg, Germany, 2003.

Roeckner, E., Brokopf, R., Esch, M., Giorgetta, M. A., Hagemann, S., Kornblueh, L., Manzini, E., Schlese, U., and Schulzweida, U.: Sensitivity of Simulated Climate to Horizontal and Vertical Resolution in the ECHAM5 Atmosphere Model, J. Climate, 19, 3771-3791, 2006.

Schulz, M., Textor, C., Kinne, S., Balkanski, Y., Bauer, S., Berntsen, T., Berglen, T., Boucher, O., Dentener, F., Guibert, S., Isaksen, I. S. A., Iversen, T., Koch, D., Kirkevåg, A., Liu, X., Montanaro, V., Myhre, G., Penner, J. E., Pitari, G., Reddy, S., Seland, Ø., Stier, P., and Takemura, T.: Radiative forcing by aerosols as derived from the AeroCom present-day and pre-industrial simulations, Atmos. Chem. Phys., 6, 5225-5246, doi:10.5194/acp-6-5225-2006, 2006.

Seinfeld, J. H. and Pandis, S. N.: Atmospheric Chemistry and Physics: From Air Pollution to Climate Change, J. Wiley, New York, 1998.

Slinn, S. A. and Slinn, W. G. N.: Predictions for particle deposition on natural waters, Atmos. Environ., 14, 1013-1026, 1980.

Smith, M. and Harrison, N.: The sea spray generation function, J. Aerosol Sci., 29, 189-190, 1998.

Spracklen, D. V., Pringle, K. J., Carslaw, K. S., Chipperfield, M. P., and Mann, G. W.: A global off-line model of sizeresolved aerosol microphysics: I. Model development and prediction of aerosol properties, Atmos. Chem. Phys., 5, 22272252, doi:10.5194/acp-5-2227-2005, 2005.

Stevens, B. and Feingold, G.: Untangling aerosol effects on clouds and precipitation in a buffered system, Nature, 461, 607-613, 2009.

Stier, P., Feichter, J., Kinne, S., Kloster, S., Vignati, E., Wilson, J., Ganzeveld, L., Tegen, I., Werner, M., Balkanski, Y., Schulz, M., Boucher, O., Minikin, A., and Petzold, A.: The aerosolclimate model ECHAM5-HAM, Atmos. Chem. Phys., 5, 11251156, doi:10.5194/acp-5-1125-2005, 2005.

Tegen, I. and Lacis, A. A.: Modeling of particle size distribution and its influence on the radiative properties of mineral dust aerosol, J. Geophys. Res., 101, 19237-19244, doi:10.1029/95JD03610, 1996.

Tegen, I., Harrison, S. P., Kohfeld, K., Prentice, I. C., Coe, M., and Heimann, M.: Impact of vegetation and preferential source areas on global dust aerosol: Results from a model study, J. Geophys. Res., 107, 4576-4597, 2002.

Textor, C., Schulz, M., Guibert, S., Kinne, S., Balkanski, Y., Bauer, S., Berntsen, T., Berglen, T., Boucher, O., Chin, M., Dentener, F., Diehl, T., Easter, R., Feichter, H., Fillmore, D., Ghan, S., Ginoux, P., Gong, S., Grini, A., Hendricks, J., Horowitz, L., Huang, P., Isaksen, I., Iversen, I., Kloster, S., Koch, D., Kirkevåg, A., Kristjansson, J. E., Krol, M., Lauer, A., Lamarque, J. F., Liu,
X., Montanaro, V., Myhre, G., Penner, J., Pitari, G., Reddy, S., Seland, Ø., Stier, P., Takemura, T., and Tie, X.: Analysis and quantification of the diversities of aerosol life cycles within AeroCom, Atmos. Chem. Phys., 6, 1777-1813, doi:10.5194/acp-61777-2006, 2006.

Textor, C., Schulz, M., Guibert, S., Kinne, S., Balkanski, Y., Bauer, S., Berntsen, T., Berglen, T., Boucher, O., Chin, M., Dentener, F., Diehl, T., Feichter, J., Fillmore, D., Ginoux, P., Gong, S., Grini, A., Hendricks, J., Horowitz, L., Huang, P., Isaksen, I. S. A., Iversen, T., Kloster, S., Koch, D., Kirkevåg, A., Kristjansson, J. E., Krol, M., Lauer, A., Lamarque, J. F., Liu, X., Montanaro, V., Myhre, G., Penner, J. E., Pitari, G., Reddy, M. S., Seland, Ø., Stier, P., Takemura, T., and Tie, X.: The effect of harmonized emissions on aerosol properties in global models an AeroCom experiment, Atmos. Chem. Phys., 7, 4489-4501, doi:10.5194/acp-7-4489-2007, 2007.

Tiedtke, M.: A comprehensive mass flux scheme for cumulus parameterization in large scale models, Mon. Weather Rev., 117, 1779-1800, 1989.

Timmreck, C. and Schulz, M.: Significant dust simulation differences in nudged and climatological operation mode of the AGCM ECHAM, J. Geophys. Res., 109, D13202, doi:101029/2003JD004381, 2004.

Vehkamaki, H.: An improved parameterization for sulfuric acidwater nucleation rates for tropospheric and stratospheric conditions, J. Geophys. Res., 107, 4622, doi:10.1029/2002JD002184, 2002.

Vignati, E., Wilson, J., and Stier, P.: M7: An efficient size-resolved aerosol microphysics module for large-scale aerosol transport models, J. Geophys. Res., 109, D22202, doi:10.1029/2003JD004485, 2004.

Wan, H., Wang, B., Yu, R., et al.: Development and validation of the gridpoint atmospheric model of IAP LASG (GAMIL), Technical Report 16, LASG, Institute of Atmospheric Physics, Chinese Academy of Sciences, Beijing, China, 2006.

Wang, B., Wan, H., Ji, Z., et al.: Design of a new dynamical core for global atmospheric models based on some efficient numerical methods, Science in China, Series A, 47, 4-21, 2004.

Weisenstein, D. K., Yue, G. K., Ko, M. K. W., Sze, N. D., Rodriguez, J. M., and Scott, C. J.: A two-dimensional model of sulfur species and aerosol, J. Geophys. Res., 102, 13019-13035, 1997.

Whitby, E. R. and McMurry, P. H.: Modal aerosol dynamics modeling, Aerosol Sci. Tech., 27, 673-688, 1997.

Whitby, E. R., McMurry, P. H., Binkowski, F., and Shankar, U.: Modal Aerosol Dynamics Modeling, Report for Contract 68-017365, EPA, 1991.

Williamson, D. L. and Rasch, P. J.: Two-dimensional semiLagrangian transport with shape-preserving interpolation, Mon. Weather Rev., 117, 102-129, 1989.

Wilson, J., Cuvelier, C., and Raes, F.: A modeling study of global mixed aerosol fields, J. Geophys. Res., 106, 34081-34108, 2001.

Wilson, J. F. R.: M3 multi-modal model for aerosol dynamics, in: Nucleation and Atmospheric Aerosol, edited by: Kulmala, M. and Wagner, P. E., Elsevier, Oxford, UK, 1996.

Zender, C. S., Bian, H., and Newman, D.: The mineral Dust Entrainment And Deposition (DEAD) model: Description and 1990s dust climatology, J. Geophys. Res., 108, 4416, doi:10.1029/2002JD002775, 2003. 
Zhang, G. J. and McFarlane, N. A.: Sensitivity of climate simulations to the parameterization of cumulus convection in the Canadian Climate Centre general circulation model, Atmos.-Ocean, 33, 407-446, 1995.

Zhang, K.: Tracer transport evaluation and aerosol simulation with the atmospheric model GAMIL-LIAM, Ph.D. thesis, Insitute of Atmospheric Physics, Chinese Academy of Sciences, Beijing, China, PhD thesis in Chinese, 2008.

Zhang, K., Wan, H., Zhang, M., and Wang, B.: Evaluation of the atmospheric transport in a GCM using radon measurements: sensitivity to cumulus convection parameterization, Atmos. Chem. Phys., 8, 2811-2832, doi:10.5194/acp-8-2811-2008, 2008.
Zhang, L., Gong, S., Padro, J., and Barrie, L.: A size-segregated particle dry deposition scheme for an atmospheric aerosol module, Atmos. Environ., 35, 549-560, 2001.

Zhang, M., Lin, W., Bretherton, C., Hack, J., and Rasch., P. J.: A modified formulation of fractional stratiform condensation rate in the NCAR Community Atmospheric Model (CAM2), J. Geophys. Res., 108, 4035, doi:10.1029/2002JD002523, 2003. 